\title{
Microstructure-strength relationship in friction-stir welded 6061-T6 aluminum alloy
}

\author{
Alexander Kalinenko, Konstantin Kim, Igor Vysotskiy, Ivan Zuiko, Sergey Malopheyev, \\ Sergey Mironov", Rustam Kaibyshev \\ Laboratory of Mechanical Properties of Nanoscale Materials and Superalloys, Belgorod National Research University, Pobeda 85, Belgorod, 308015, Russia
}

\section{A R T I C L E I N F O}

\section{Keywords:}

Heat-treatable aluminium alloys

Friction-stir welding

Precipitates

Microstructure-strength relationship

\begin{abstract}
A B S T R A C T
In this work, a structural response of 6061-T6 aluminum alloy to friction-stir welding (FSW) was studied in wide range of processing conditions in order to establish a better foundation for the microstructure-strength relationship in produced welds. In contrast to the widely-accepted conception of the FSW-induced precipitation behavior, the welding temperature was found to be often below the dissolution threshold and thus no particle dissolution took place. Moreover, the peak temperature never exceeded $500{ }^{\circ} \mathrm{C}$, and therefore the particles never dissolved completely. Considering a relatively low cooling rate measured in the stir zone, the dissolved precipitates were suggested to partially re-precipitate as solute clusters during weld cooling cycle thus imparting a substantial hardening effect. Accordingly, the precipitation coarsening was deduced to be the major softening mechanism. Due to the extreme sensitivity of this process to a duration of the weld thermal cycle, the welding speed was surmised to be the key factor controlling weld strength.
\end{abstract}

\section{Introduction}

Due to the attractive combination of high specific strength, excellent ductility, good corrosion resistance and relatively low cost, heattreatable aluminum alloys are widely applied in transportation industry. Unfortunately, a poor weldability of these materials by conventional fusion techniques necessitates using a riveting technique as a typical joining approach. This, however, degrades performance of the welded structures and increases their manufacturing cost. In this regard, friction-stir welding (FSW), an innovative technology, is often considered as promising candidate for joining of these alloys [1,2]. Being a solid-state technique, it avoids solidification phenomena associated with fusion welding and thus enables sound joining of even "unweldable" materials.

Considering significant industrial potential of FSW for joining of heat-treatable aluminum alloys, considerable research efforts have been undertaken recently in this direction. Since the properties of such materials are governed by the constituent nano-scale dispersoids, a particular emphasis has been given to the investigation of the underlying precipitation behavior. It has been found that significant temperature gradient inherent to the FSW process leads to complex precipitation phenomena in the welded materials. Specifically, the microstructural areas exposed at relatively low temperatures (i.e., the so-called heataffected zone) typically exhibit an essential coarsening of the constituent particles [3-28] which, in turn, normally results in the concomitant coherency loss $[11,17,29]$. With increasing of the welding temperature towards the stir zone (i.e., the microstructural region experiencing the highest heat input during FSW), the particles are believed to completely dissolve [3-7,9,11,12,14-18,20,30-36]. All above processes give rise to material softening and thus essentially degrade the weld strength $[6,7$, $12,15,17,37,38]$. It is important to emphasize that some fraction of the dissolved particles may re-precipitate during weld cooling cycle thus partially restoring the material strength $[3,12,15-19,30,36]$. As a result, the softening effect is usually most pronounced in the heat-affected zone. Accordingly, the microhardness profiles measured across the welded material often exhibit a characteristic W-shape [2]. During transverse tensile tests, the welds typically fail in the heat-affected zone and weld ductility is usually low.

The above microstructural behavior has been observed in various alloys belonging to all commercial systems. Therefore, there is no doubt that it reflects the intrinsic microstructural processes occurring in the welded material. On the other hand, it is important to realize that the FSW processing window for aluminum alloys is relatively broad with the peak welding temperature ranging from $150{ }^{\circ} \mathrm{C}$ to $450{ }^{\circ} \mathrm{C}$ [39]. A

\footnotetext{
* Corresponding author.

E-mail address: mironov@bsu.edu.ru (S. Mironov).
} 
significant portion of this temperature range lies below the particle dissolution temperature. It appears therefore that the precipitation phenomena in such low-temperature welds do not fit the above concept. To the best of the authors knowledge, this interval of FSW conditions in not studied well and thus our understanding of the welding behavior of the heat-treatable aluminum alloys is perhaps incomplete.

The present study was undertaken in an attempt to provide a deeper insight into this issue with the final aim to establish a better foundation for the microstructure-strength relationship. To this end, a correlation between weld thermal cycle, resulting microstructure and the weld strength was investigated in wide range of FSW variables.

\section{Experimental}

The material used in the present work was a commercial 6061 aluminum allow with nominal chemical composition (wt.\%) of $0.88 \mathrm{Mg}$, $0.66 \mathrm{Si}, 0.72 \mathrm{Fe}, 0.26 \mathrm{Cu}, 0.12 \mathrm{Mn}, 0.12 \mathrm{Cr}, 0.09 \mathrm{Zn}$, and balance Al. This is a typical heat-treatable aluminum alloy which is widely used in industry and whose precipitation- and FSW behavior is studied relatively well. The material was produced by semi-continuous casting, homogenized at $380{ }^{\circ} \mathrm{C}$ for $1 \mathrm{~h}$ and then extruded at the same temperature to $75 \%$ of area reduction. To obtain the peak-aged condition, the extruded material was T6-tempered, i.e., solutionized at $550{ }^{\circ} \mathrm{C}$ for $1 \mathrm{~h}$, water quenched at then artificially aged at $160{ }^{\circ} \mathrm{C}$ for $8 \mathrm{~h} .{ }^{1}$ This material condition was referred as base material throughout the manuscript. The microstructure of the base material was dominated by mm-scale elongated grains which contained developed subboundary structure and high density of nano-scale $\beta^{/ /}$dispersoids evenly distributed in grain interior (Supplementary Figs. S2a and b). It is worth noting that the base material also contained a relatively high fraction of coarse grainboundary particles enriched by silicon, chromium and iron (Supplementary Fig. S2c) which presumably originated from solidification process. Further microstructural details have been described elsewhere [40].

The T6-tempered material was sliced into welding sheets of $3 \mathrm{~mm}$ in thickness and friction-stir welded along extrusion direction by using an AccurStir 1004 FSW machine. The welding tool was manufactured from a tool steel and consisted of a shoulder of $12.5 \mathrm{~mm}$ in diameter and an M5 cylindrical probe of $2.7 \mathrm{~mm}$ in length. To investigate the material behavior in the entire FSW processing window, the spindle- and the feed rates were systematically varied in wide range, as shown in Table 1 . This range was determined by the capabilities of the used FSW machine as well as a formation of welding defects. In all cases, the tool tilting angle of $2.5^{\circ}$ was employed and stainless steel was used as a backing plate. To distinguish the different welds throughout the manuscript, the $\mathrm{N} \times \mathrm{V}$ code was used (where $\mathrm{N}$ is the spindle rate and $\mathrm{V}$ is the feed rate), as shown in Table 1. The principal directions of FSW geometry were denoted as welding direction (WD), transverse direction (TD), and normal direction (TD).

To record the weld thermal cycle in the heat-affected zone and the stir zone, K-type thermocouples were placed as close as possible to the

Table 1

Designation of welds.

\begin{tabular}{llll}
\hline Spindle rate, rpm & \multicolumn{4}{l}{ Feed rate, mm/min } \\
\cline { 2 - 4 } & 125 & 380 & 760 \\
\hline 500 & $500-125$ & $500-380$ & - \\
750 & $750-125$ & $750-380$ & $750-760$ \\
1100 & $1100-125$ & $1100-380$ & $1100-760$ \\
\hline
\end{tabular}

$\overline{1}$ The aging hardness curve is shown in Supplementary Fig. S1. shoulder edge and to the stir zone border, respectively (Supplementary Fig. S3).

To minimize the possible influence of natural aging, the welded material was stored in a freezer at $-20{ }^{\circ} \mathrm{C}$ prior to examinations.

Microstructural observations were conducted with optical microscopy, electron backscatter diffraction (EBSD), transmission electron microscopy (TEM), and energy-dispersive x-ray spectroscopy (EDS). For optical and EBSD examinations, the specimens were machined transverse to the WD across the entire weld zone. For TEM, the specimens were cut precisely from the heat-affected zone and the stir zone. The samples for optical observations were prepared by a mirror-polishing using conventional mechanical-polishing technique, and then chemically etched with Keller's reagent. A suitable surface finish for EBSD and TEM was obtained by electro-polishing in a solution of $25 \%$ nitric acid in methanol.

EBSD analysis was performed by using an FEI Quanta 600 fieldemission-gun scanning electron microscopy (FEG-SEM) equipped with TSL OIM ${ }^{\mathrm{TM}}$ software and operated at accelerated voltage of $30 \mathrm{kV}$. Depending on a scale of particular microstructure, a scan step size of 0.5 or $1 \mu \mathrm{m}$ was used. A $15^{\circ}$ criterion was employed to differentiate lowangle boundaries (LABs) from high-angle boundaries (HABs).

TEM observations were conducted with JEOL JEM-2100EX transmission electron microscope equipped with an INCA EDS system and operating at $200 \mathrm{kV}$. To enhance the contrast associated with dispersoids of the $\beta$ //phase, the TEM specimens were typically tilted to align the incident electron beam with a $<100>$ zone axis. The foil thickness, $t$, was determined by the convergent-beam-electron-diffraction method using Kossel-Mollenstedt fringes under two-beam condition [41]. In the base material and the heat-affected zone, where the second-phase particles had a needle-shaped morphology and were aligned with $<100>$ direction, their number density per unit volume (PND) was calculated as $N_{v}=\frac{3}{2} \frac{N_{m}}{A t}$, where $N_{m}$ was the measured PND, and $A$ was the surface area. The volume fraction of the precipitates in these microstructural regions was calculated as $f=N_{v} \frac{\pi d^{2}}{4} L$, where $d$ and Lwere the mean thickness and the mean length of the needle-shaped particles, respectively. In the stir zone, where the dispersoids acquired a nearly-equiaxed shape, the particle volume fraction was determined as $f=\frac{N_{m}}{A t} \frac{\pi D^{3}}{6}$, where $D$ was the mean particle diameter.

To provide a broad view on microstructure distribution within the welded material, microhardness profiles were measured across the weld midthickness. Vickers microhardness data were obtained by applying a load of $200 \mathrm{~g}$ with a dwell time of $10 \mathrm{~s}$, using a Wolpert 402MVD microhardness tester.

The mechanical behavior of the welds was investigated by using transverse tensile tests. The tensile specimens were machined perpendicular to the WD, and were centered along the weld centerline. The specimens had a gauge section of $30 \mathrm{~mm}$ in length and $7 \mathrm{~mm}$ in width, and included all characteristic microstructural zones generated during FSW. The upper and lower surfaces of the specimens were mechanically polished to achieve a uniform thickness and remove the kissing bond defect at the weld root. For comparative purposes, appropriate tensile specimens were also machined from the base material. The tension tests to failure were conducted at ambient temperature and a constant crosshead velocity corresponding to a nominal strain rate of $10^{-3} \mathrm{~s}^{-1}$. An Instron 5882 universal testing machine equipped with an automatic high-resolution contacting extensometer was used for the tests. At least four tensile specimens were tested for each material condition. Fracture surfaces were examined with the FEI Quanta 600 FEG-SEM.

To investigate the distribution of local strains produced during the tensile tests, digital image correlation (DIC) technique was employed. The in-plane Lagrangian strains were measured on all specimen surfaces by using commercial Vic-3D system. For the measurements, a random ink pattern was applied to the sample surface prior the tests and high speed camera was used for the image recording during the tests.

To facilitate interpretation of microstructural changes occurring 
during FSW, thermodynamic calculations were performed by using ThermoCalc 2020a software with the TCAl1 database.

\section{Results}

\subsection{ThermoCalc predictions}

It is well accepted that mechanical behavior of 6061-T6 aluminum alloy is primarily governed by nano-scale $\beta$ / precipitates and, to some extent, $Q^{\prime}$ dispersoids. Since these phases are unstable, their precipitation behavior is difficult to predict by conventional thermodynamic calculations. Nevertheless, attempting to provide at least indirect insight into this issue, the evolution of equilibrium phases was simulated by using ThermoCalc software with the obtained results being shown in Fig. 1 and Supplementary Fig. S4.$^{2}$

Below $\sim 220^{\circ} \mathrm{C}$, the fractions of $\mathrm{Q}$ and $\beta$ phases were predicted to change only slightly (Fig. 1). In the range of $220-300{ }^{\circ} \mathrm{C}$, the $\mathrm{Q}$ phase was expected to dissolve but this process would be nearly-compensated by precipitation of additional $\beta$ phase (Fig. $1 \mathrm{a}$ and b, respectively). Above $300{ }^{\circ} \mathrm{C}$, the $\beta$ phase was also predicted to gradually dissolve and this process was expected to complete at $502.5^{\circ} \mathrm{C}$ (Fig. 1b).

\subsection{Temperature measurements}

In order to establish a relationship between the welding variables and the FSW-induced heat input, the weld thermal cycle was systematically measured. The obtained results were summarized in Figs. 2 and 3, Supplementary Figs. S5-S7, and Supplementary Table S1. As expected, the peak welding temperature typically raised with the spindle rate (Fig. 2a). On the other hand, an increase in the feed rate usually resulted in essential narrowing of the weld thermal cycle and reduction of the welding temperature (Fig. 2b). Accordingly, the highest welding temperatures were recorded at the combination of high spindle rate and low feed rate (Fig. 3a).

Depending on welding conditions, the peak temperature in the heataffected zone varied from $159{ }^{\circ} \mathrm{C}$ to $248{ }^{\circ} \mathrm{C}$; on the other hand, the highest temperature in the stir zone ranged from $254{ }^{\circ} \mathrm{C}$ to $416{ }^{\circ} \mathrm{C}$ (Supplementary Table S1). Importantly, the temperatures well above $300{ }^{\circ} \mathrm{C}$ (i.e., the dissolution threshold for the $\beta$ phase) was recorded only at 3 welding conditions out of 8 ones studied in the present work. Moreover, the peak welding temperature never exceeded $500{ }^{\circ} \mathrm{C}$ and thus the $\beta$ phase perhaps never dissolved completely.

Considering a possibility of the partial re-precipitation of the dissolved particles during weld cooling cycle reported previously [3,12, 15-19,30,36], the cooling rate of the stir zone material may be of important concern. Accordingly, the average cooling rate was evaluated $^{3}$ and summarized in Fig. 3b and Supplementary Table S1. In full accordance with expectations, the cooling rate was found to the mainly governed by the feed rate (Fig. $3 \mathrm{~b}$ ) and ranged from $12.4{ }^{\circ} \mathrm{C} / \mathrm{s}$ to 44.5 ${ }^{\circ} \mathrm{C} / \mathrm{s}$ depending on particular welding conditions. It is important to emphasize that even the highest cooling rate in the stir zone was well below $\sim 1000{ }^{\circ} \mathrm{C} / \mathrm{s}$ expected during water quenching. This perhaps means that the partial re-precipitation could, indeed, occur.

Based on the above temperature measurements, the joints produced at low welding temperatures but high cooling rates were defined throughout as low-heat-input welds. Contrarily, those obtained at high welding temperatures and low cooling rate were referred to as high-

\footnotetext{
${ }^{2}$ It should be noted that ThermoCalc software predicts equilibrium phases which are not necessarily exist in the real material. Specifically, the $\beta$ - and Q phases are typically not observed at ambient temperature.

${ }^{3}$ Assuming that the intensity of the diffusion-driven processes (including the particle re-precipitation) rapidly drops below $\sim 100{ }^{\circ} \mathrm{C}$, the average cooling rate was evaluated as $C=(T-100) / \tau$, where $T$ is the peak welding temperature (in ${ }^{\circ} \mathrm{C}$ ) and $\tau$ is the time of cooling down to $100{ }^{\circ} \mathrm{C}$ (in seconds).
}

heat-input welds.

\subsection{Microstructural observations}

\subsubsection{Low-magnification overview}

The low-magnification optical images of transverse cross sections of the produced welds are shown in Fig. 4 and Supplementary Fig. S8. In all welds, a distinct stir zone was seen. A characteristic basin-like shape of the stir zone evidenced a pronounced effect of the tool shoulder on material flow in the upper portion of the welds.

No volumetric welding defects were found in any of the joints. On the other hand, a very specific microstructural pattern observed in the bottom section of the low-heat-input welds (Fig. 4a) suggested a possibility of tool wear. Though this effect is usually observed in titanium alloys and steels, sometimes it is also reported for aluminum alloys [42]. In the high-heat-input welds, an elliptical-shaped nugget zone was found (Fig. 4b).

\subsubsection{Broad aspects of microstructure distribution}

To provide an insight into distribution of FSW-induced microstructures, microhardness profiles were measured across the welds with the obtained results being shown in Fig. 5 and Supplementary Fig. S9. For clarity, the probe- and shoulder diameters were indicated in the figures. To the first approximation, the probe diameter delineates stir zone whereas the shoulder diameter indicates the heat-affected zone.

In the low-heat-input welds, a pronounced material softening was found in the welded material with the minimal hardness in the stir zone (Fig. 5a). An increase in the heat input enhanced the softening effect in the heat-affected zone but surprisingly gave rise to the material strengthening in the stir zone (compare Fig. $5 \mathrm{a}$ and $\mathrm{b}$ ). As a result, the hardness level in these microstructural regions became nearlyequilibrated (Fig. 5b). With further increasing of the weld heat-input, the above opposite softening/hardening trends in the heat-affected zone and the stir zone became more pronounced thus resulting in a characteristic "W-type" shape of the microhardness profile (Fig. 5c).

Therefore, the average hardness in the stir zone increased with the weld heat input from $\sim 60 \mathrm{Hv}$ (Fig. $5 \mathrm{a}$ ) to $\sim 80 \mathrm{Hv}$ (Fig. $5 \mathrm{c}$ ).

From the microhardness measurements, two microstructural areas of particular interest were defined, i.e., the heat-affected zone and the stir zone. $^{4}$

\subsubsection{Heat-affected zone}

In the heat-affected zone, no significant changes in grain structure was revealed (not shown). To investigate precipitation phenomena, extensive TEM examinations were conducted in 500-380 and 1100-125 welds, which represented the typical low- and high-heat-input cases, respectively. The obtained results were summarized in Fig. 6 and Table 2. In these joints, the peak temperature measured in the heataffected zone was $185^{\circ} \mathrm{C}$ and $248{ }^{\circ} \mathrm{C}$, respectively, whereas a duration of thermal exposure above $100{ }^{\circ} \mathrm{C}$ was $8 \mathrm{~s}$ and $33 \mathrm{~s}$, respectively.

In both studied welds, precipitates retained their original needleshaped morphology (Fig. 6). On the other hand, a notable particle coarsening was observed (Table 2). As expected, this effect was most pronounced in the high-heat-input weld (Fig. 6, Table 2). Considering a significant increase in the particle length (up to $\sim 50 \mathrm{~nm}$ in the $500-380$ joint and $\sim 200 \mathrm{~nm}$ in the 1100-125 joint), it is likely that the original coherent $\beta^{/ /}$phase had transformed into $\beta^{\prime}$ - or even stable $\beta$ phase.

Moreover, considering the temperatures experienced in the heat-affected zone $\left(<300^{\circ} \mathrm{C}\right)$, the Q-type phase should also retain in this microstructural region (Fig. 1a). Specifically, the presence of the

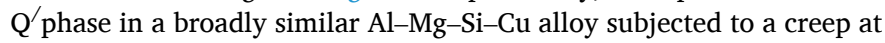
$250{ }^{\circ} \mathrm{C}$ has been recently reported by Chen et al. [43].

\footnotetext{
${ }^{4}$ The typical grain structures observed in thermo-mechanically affected zone are shown in Supplementary Figs. S10 and S11.
} 

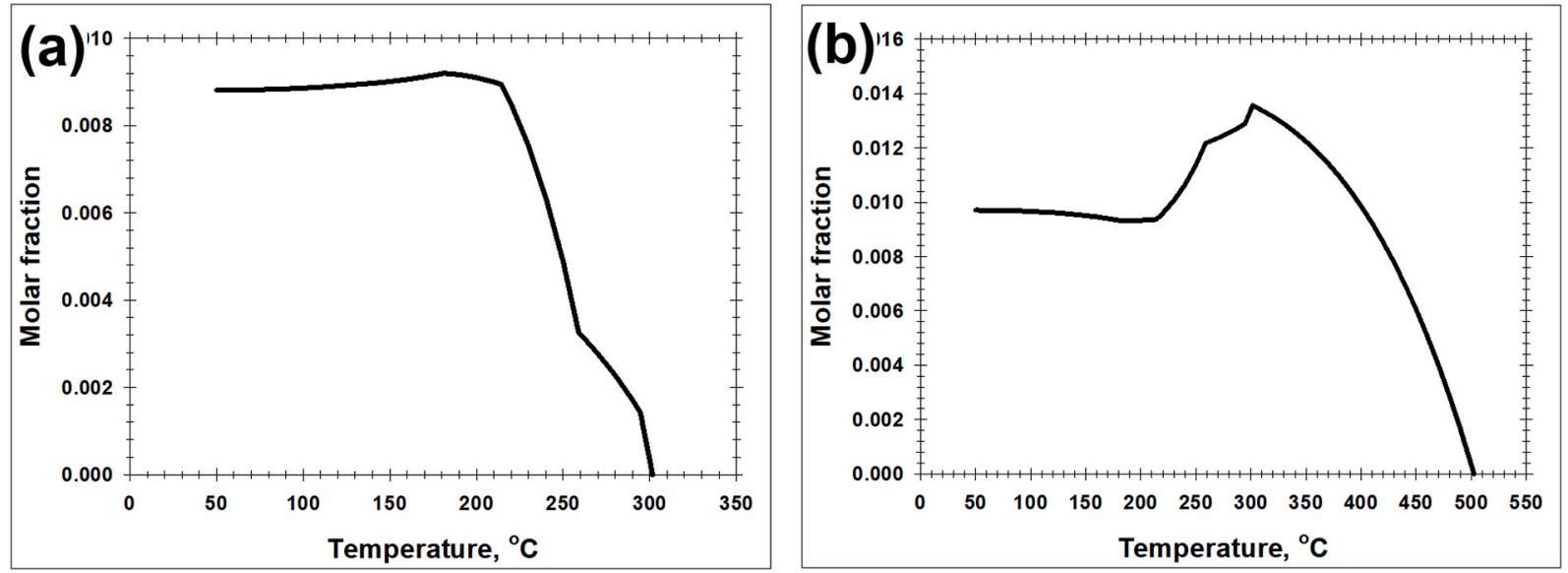

Fig. 1. ThermoCalc prediction of the temperature dependence of the molar fraction of $\mathrm{Al}_{5} \mathrm{Cu}_{2} \mathrm{Mg}_{8} \mathrm{Si}_{6}$ phase (i.e., Q-phase) (a), and $\mathrm{Mg}_{2} \mathrm{Si}$ phase (i.e., $\beta$-phase) (b).
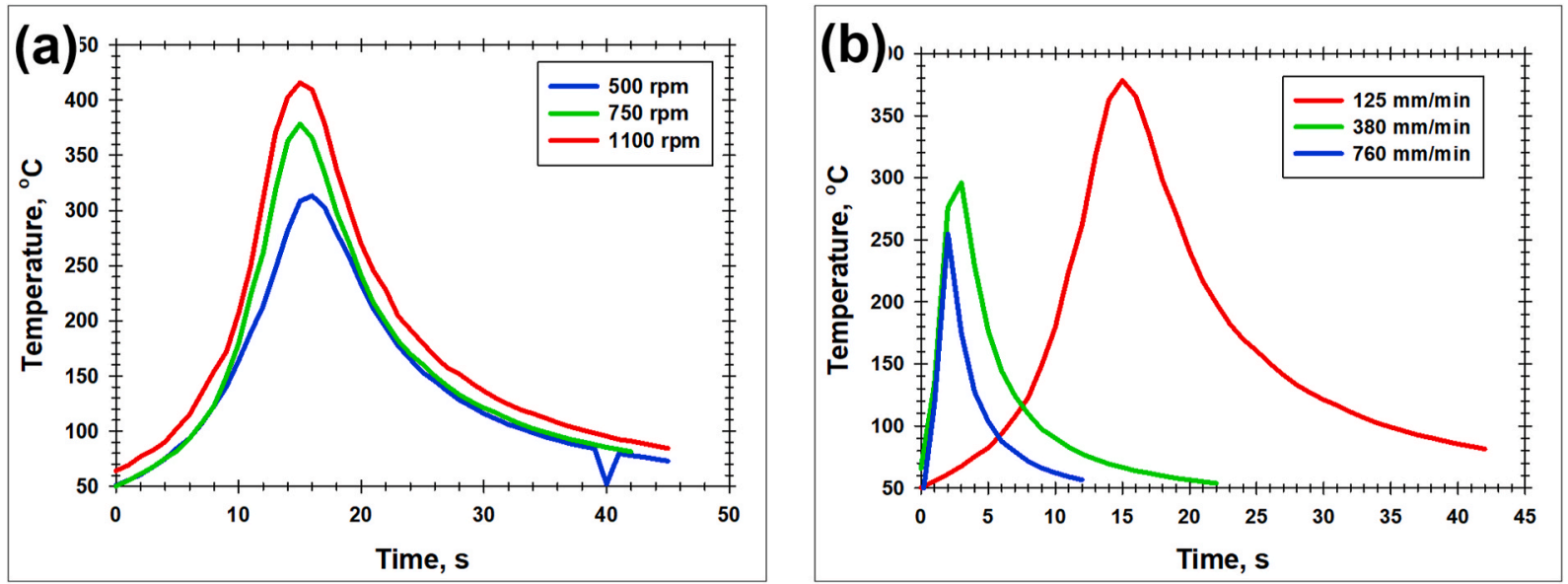

Fig. 2. Typical effect of the spindle rate (a) and feed rate (b) on the weld thermal cycle. In (a), the temperature profiles were measured at the feed rate of $125 \mathrm{~mm} /$ $\mathrm{min}$; in (b), the data were taken at the spindle rate of $750 \mathrm{rpm}$.
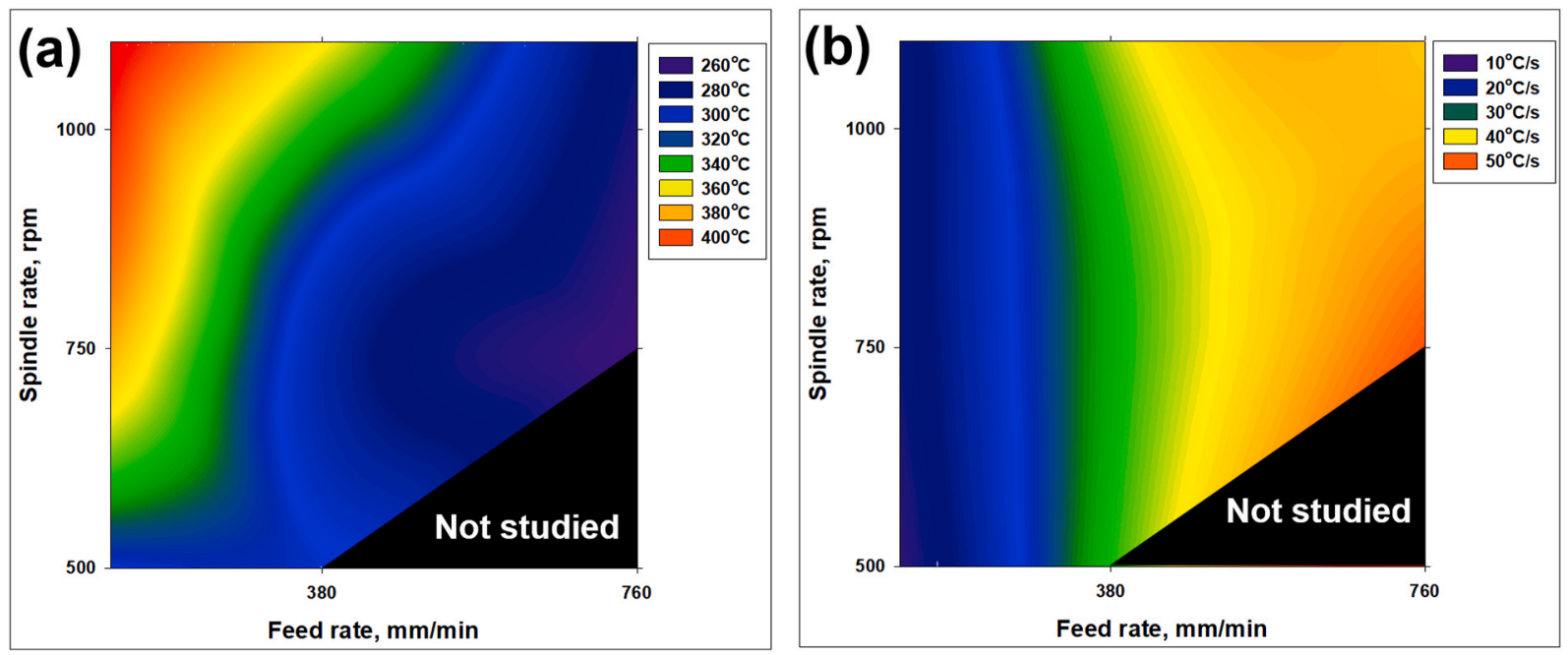

Fig. 3. Combined effect of welding variables on the peak temperature (a) and the average cooling rate (b) in the stir zone.

\subsubsection{Stir zone}

The representative EBSD grain-boundary maps taken from central section of stir zone of different welds are shown in Fig. 7 and Supplementary Fig. S12. The relevant grain-structure statistics derived from the maps is summarized in Table 3.

As follows from Fig. 7, the grain structures evolved in the stir zones of the low- and high-heat-input welds were qualitatively similar to each other. Specifically, all microstructures were dominated by nearly- 

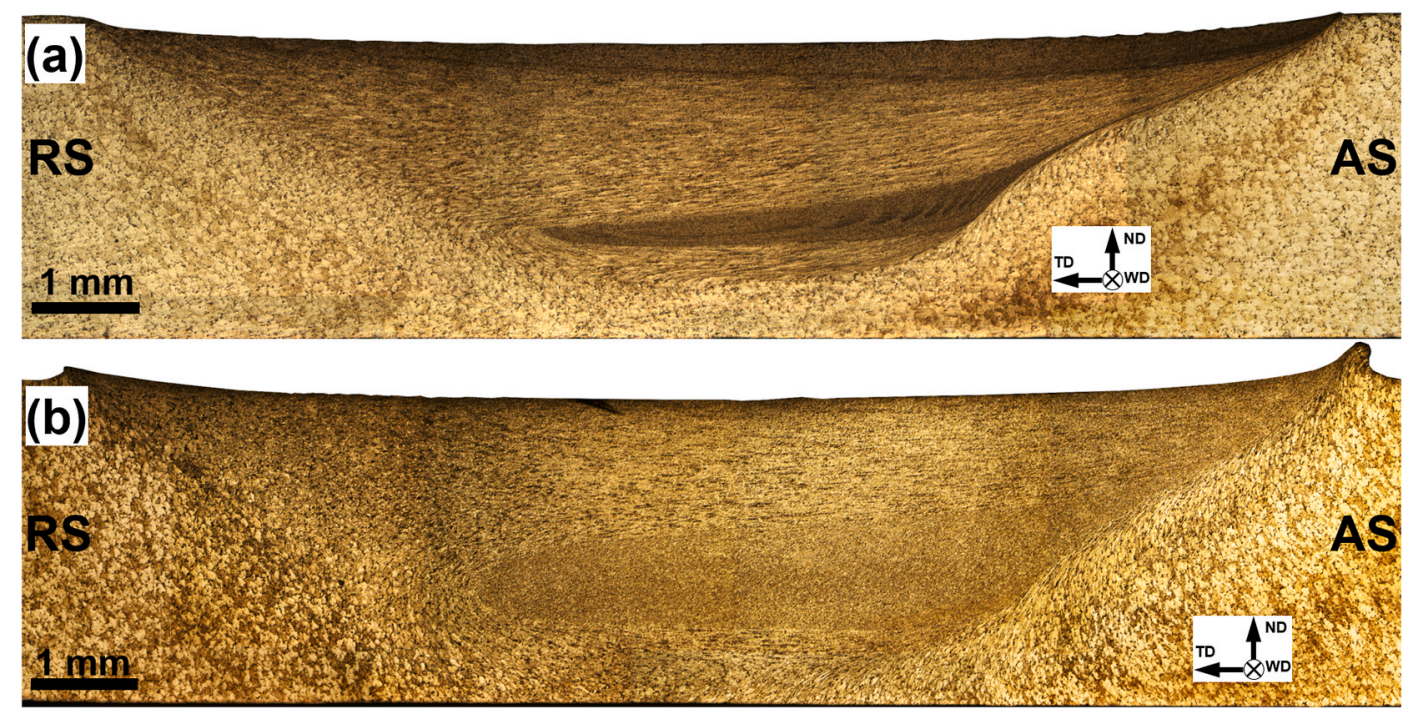

Fig. 4. Low-magnification optical images showing transverse cross-section of 500-380 weld (i.e., a low heat-input weld) (a) and of 1100-125 weld (i.e., a high heatinput weld) (b). RS and AS abbreviate retreating side and advancing side, respectively.
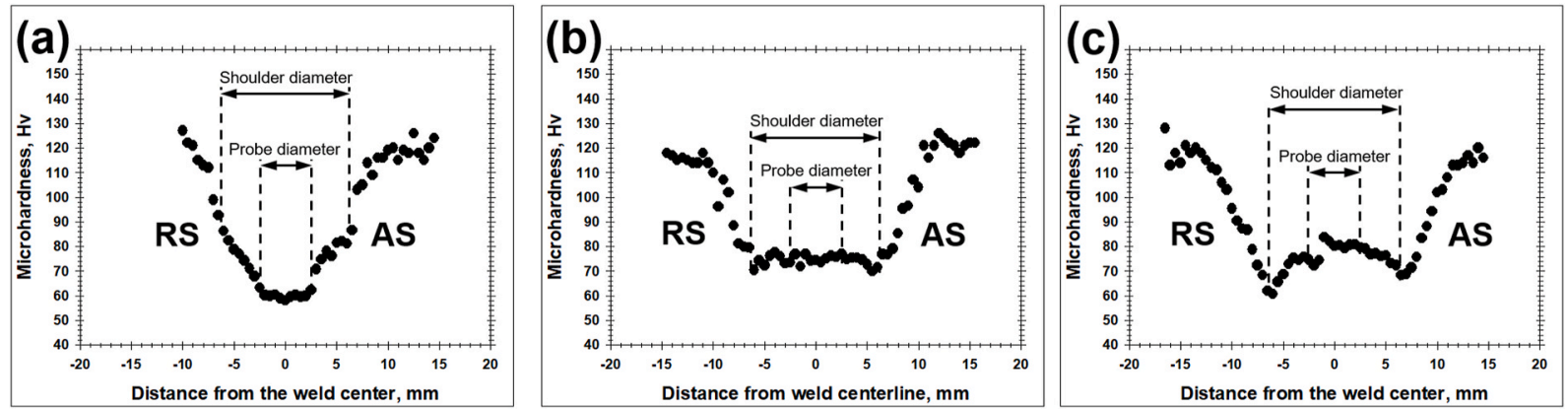

Fig. 5. Microhardness profiles measured across transverse cross-section of 500-380 weld (i.e., a low heat-input weld) (a), of 1100-380 weld (b), and 1100-125 weld (i.e., a high heat-input weld) (c). In all cases, RS and AS abbreviate retreating side and advancing side, respectively.
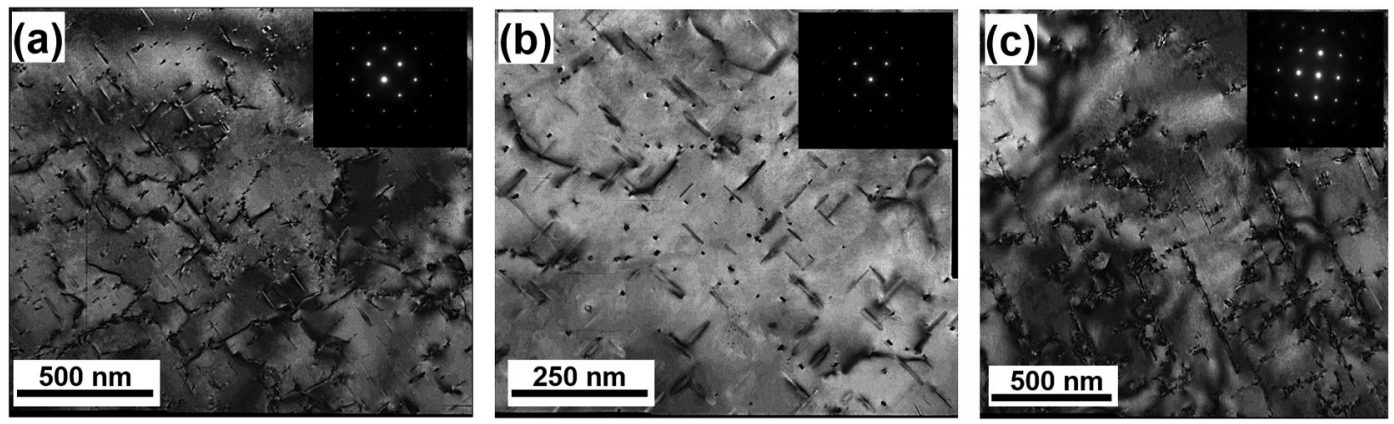

Fig. 6. TEM micrographs and micro-diffraction patters (inserts) showing precipitation patterns evolved in the heat-affected zone of 500-380 weld (i.e., a low heatinput weld) (a, b), and the 1100-125 weld (i.e., a high heat-input weld) (c). Note: In all cases, the material is shown in the near- $<100>$ orientation to emphasize the dispersoids of $\beta^{\prime \prime} / \beta^{\prime}$ phases.

equiaxed grains which contained a developed LAB network. Depending on particular welding conditions, the mean $\mathrm{HAB}$ intercept ranged from 2 to $7 \mu \mathrm{m}$, whereas $\mathrm{HAB}$ fraction - from 62 to $77 \%$ (Table 3 ).

To investigate precipitation pattern, TEM observations were made in two representative welds, i.e., the $500-380$ and $1100-125$ ones. The peak welding temperatures in these joints were $301{ }^{\circ} \mathrm{C}$ and $416{ }^{\circ} \mathrm{C}$, respectively. The characteristic TEM images taken from these joints are shown in Fig. 8, and the key microstructural statistics is given in Table 2.

As follows from Fig. 8, the second-phase particles revealed in the stir zone were characterized by equiaxed morphology and relatively coarse size. These observations presumably indicated a transformation of original $\beta / /$ dispersoinds into stable $\beta$ phase. Another important issue was a relatively low dislocation density which presumably reflected a recrystallization occurred during FSW.

Despite the partial dissolution of the $\beta$ phase predicted by thermodynamic calculations (Fig. 1), the volume fraction of the secondary particles was surprisingly found to increase (Table 2). This effect was most pronounced in the low-heat-input weld, in which the particle content increased by an order of magnitude (Table 2). The possible explanation for this unexpected result may be a fragmentation and 
Table 2

Characteristics of precipitates in selected welds.

\begin{tabular}{|c|c|c|c|c|c|}
\hline \multirow[t]{2}{*}{ Welds } & \multirow{2}{*}{$\begin{array}{l}\text { Base } \\
\text { material }\end{array}$} & \multicolumn{2}{|c|}{ Heat-affected zone } & \multicolumn{2}{|l|}{ Stir zone } \\
\hline & & $\begin{array}{l}\text { Mean } \\
\text { particle } \\
\text { width }(d) \text {, } \\
\mathrm{nm}\end{array}$ & $\begin{array}{l}\text { Volume } \\
\text { fraction } \\
(f)\end{array}$ & $\begin{array}{l}\text { Mean } \\
\text { particle } \\
\text { diameter } \\
(d), \mathrm{nm}\end{array}$ & $\begin{array}{l}\text { Volume } \\
\text { fraction } \\
(f)\end{array}$ \\
\hline $500-380$ & 5 & 7.6 & 0.0045 & 43 & 0.0184 \\
\hline 1100-125 & & 13 & 0.0026 & 69 & 0.0046 \\
\hline
\end{tabular}

Note: The dispersoids measured in the base material presumably belonged to the $\beta^{\prime \prime}$ - and Q'phases, whereas these in the heat-affected zone were most likely represented by $\beta^{\prime}$ (or $\beta$ ) and $Q$ phases. On the other hand, the precipitates in the stir zone were additionally contributed by the Fe- and Cr-rich former grainboundary particles, which have been dispersed during FSW.

subsequent dispersion of coarse grain-boundary particles present in the base material due to the stirring effect of the rotating tool. Indeed, EDS measurements revealed the Fe- and Cr-rich particles in the stir zone (Supplementary Fig. S13).

\subsection{Tensile behavior}

\subsubsection{Deformation diagrams}

Effect of welding variables on mechanical properties of welds is shown in Figs. 9 and 10, Table 4 and Supplementary Fig. S14. From the deformation diagrams in Fig. 9a and b, it was evident that the welded material exhibited relatively low strength and ductility. Depending on welding conditions, the joint efficiency for yield strength ranged from $44 \%$ to $64 \%$ (Fig. 10a), whereas that for ductility varied from $35 \%$ to 60\% (Fig. 10b).

It is interesting to note that the weld strength increased with the feed rate (Figs. 9b and 10a). Moreover, this welding parameter appears to be the major factor governing the yield strength (Fig. 10a).

On the other hand, a relationship between the welding variables and the weld ductility was relatively complex. From Fig. 10b, it seems that the highest-heat-input joints exhibited the lowest ductility.

Another remarkable issue was a fracture location. As follows from Table 4, the low-heat-input welds typically failed in the stir zone whereas the high-heat-input ones fractured in the heat-affected zone.

\subsubsection{Distribution of local strains}

In order to provide an additional insight into the tensile behavior, the distribution of local strains as function of global elongation was measured by using DIC technique. The obtained results were shown in Figs. 11-13 and Supplementary Figs. S15-S19.

As follows from a comparison of the DIC results with microhardness measurements in Fig. 5, the tensile strain in all welds was preferentially concentrated in the softened regions. On the other hand, the base material experienced almost no plastic deformation.

In the low-heat-input welds (Fig. 11), the plastic strain was preferentially concentrated in the stir zone, being most pronounced at the weld root. With increasing of the global elongation, the local strain gradually propagated in the upwards direction thus encompassing the entire stir zone (Fig. 11a-f). The failure occurred in the stir zone and most likely also initiated from the weld root (Fig. 11g).

An increase in the weld heat input resulted in a broadening of the plastically-deformed area (Fig. 12) thus presumably reflecting a widening of the softened area (Fig. 5b). Within this region, a strain clustering was observed in the heat-affected zone and the bottom section of the stir zone (Fig. 12a-d). With increase in tensile deformation, however, the local strain tended to concentrate in the former microstructural region thereby leading to a premature failure in the heat affected zone (Fig. 12e-g).

In the highest heat-input welds (Fig. 13), the tensile strain was highly localized in the heat-affected zone during entire tensile test (though the stir zone also experienced some strain). It is interesting to note that the local failure strain in the heat-affected zone was essentially lower than that in the stir zone, i.e. $15 \%$ vs 56\% (compare Figs. $13 \mathrm{~g}$ and $11 \mathrm{~g}$ ). Therefore, the relatively low ductility of the high-heat-input welds

Table 3

Characteristics of grain structure in stir zone.

\begin{tabular}{lll}
\hline Welds & Mean HAB intercept, $\mu \mathrm{m}$ & $\mathrm{HAB}$ fraction $\left(\mathrm{f}_{\mathrm{HAB}}\right) \%$ \\
\hline $500-125$ & $2.7 \pm 2.3$ & 71 \\
$500-380$ & $1.9 \pm 1.6$ & 74 \\
$750-125$ & $6.1 \pm 5.6$ & 62 \\
$750-380$ & $2.4 \pm 1.7$ & 77 \\
$750-760$ & $2.1 \pm 1.6$ & 73 \\
$1100-125$ & $7.2 \pm 5.5$ & 68 \\
$1100-380$ & $6.2 \pm 4.8$ & 66 \\
$1100-760$ & $4.4 \pm 3.8$ & 70 \\
\hline
\end{tabular}

Note: Error shows standard deviation.
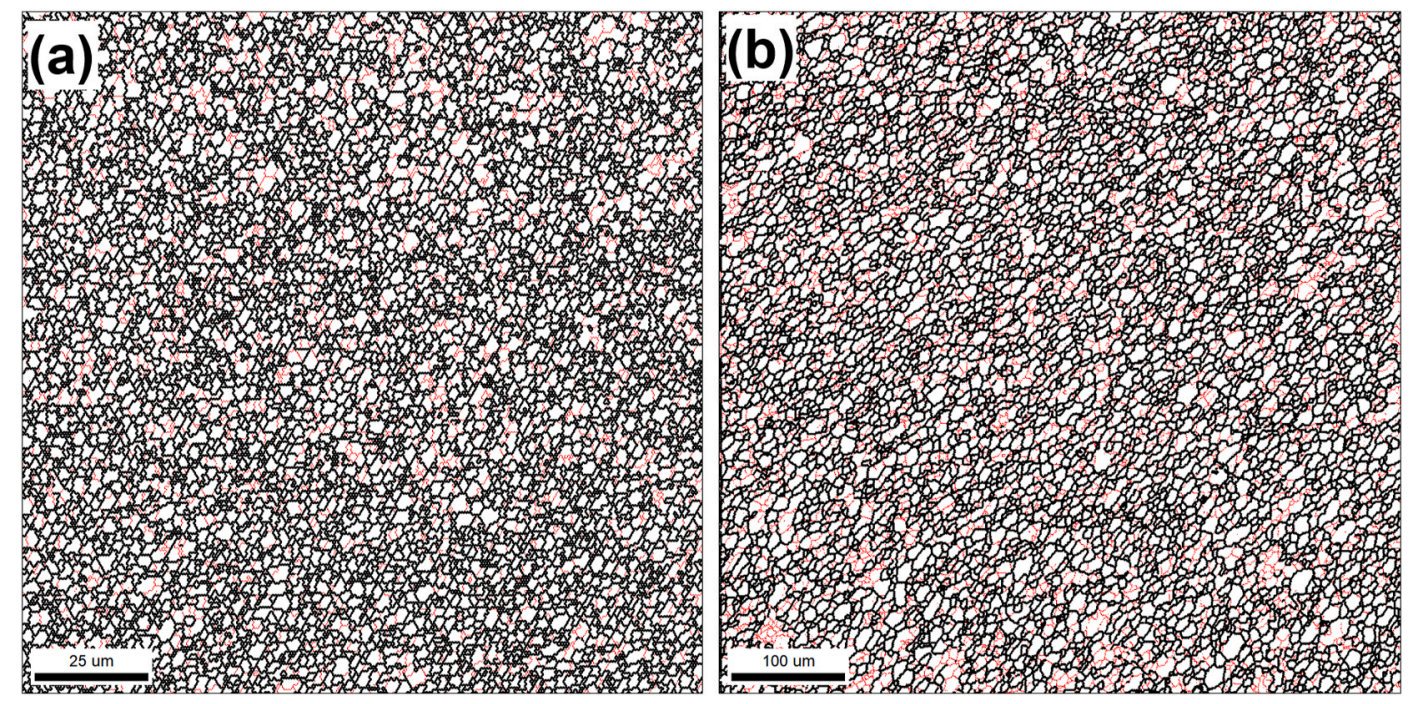

Fig. 7. EBSD grain-boundary maps showing microstructure evolved in the central section of stir zone of the 500-380 weld (i.e., a low heat-input weld) (a), and the 1100-125 weld (i.e., a high heat-input weld) (b). In the maps, LABs and HABs are depicted as red and black lines. (For interpretation of the references to colour in this figure legend, the reader is referred to the Web version of this article.) 

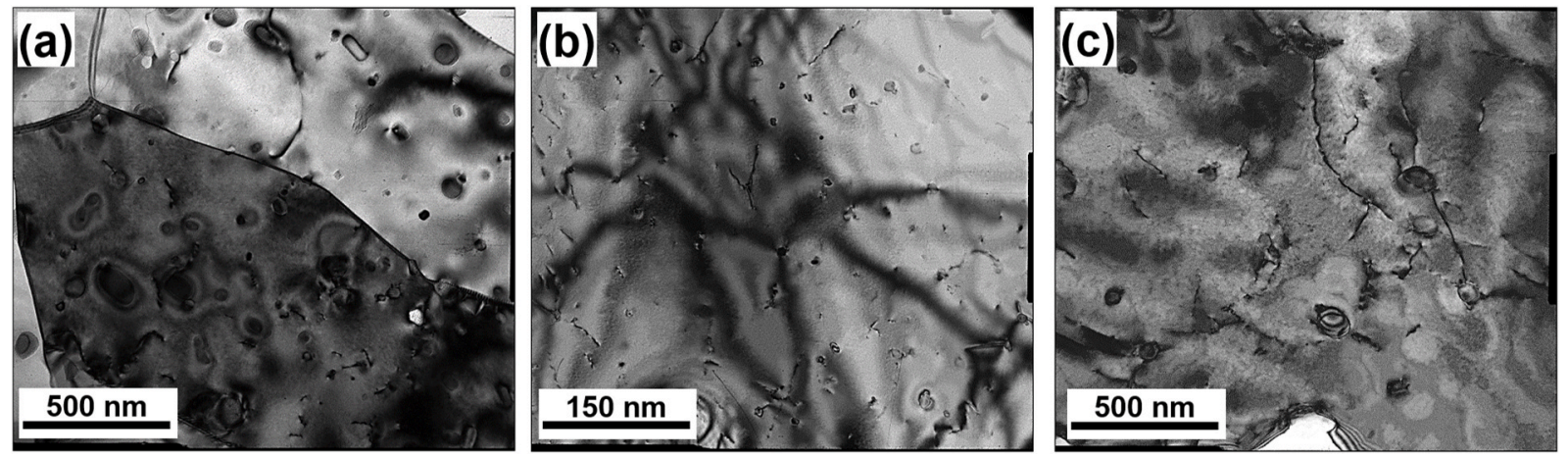

Fig. 8. TEM micrographs showing precipitation patterns evolved in the stir zone of 500-380 weld (i.e., a low heat-input weld) (a), and the 1100-125 weld (i.e., a high heat-input weld) (b, c).
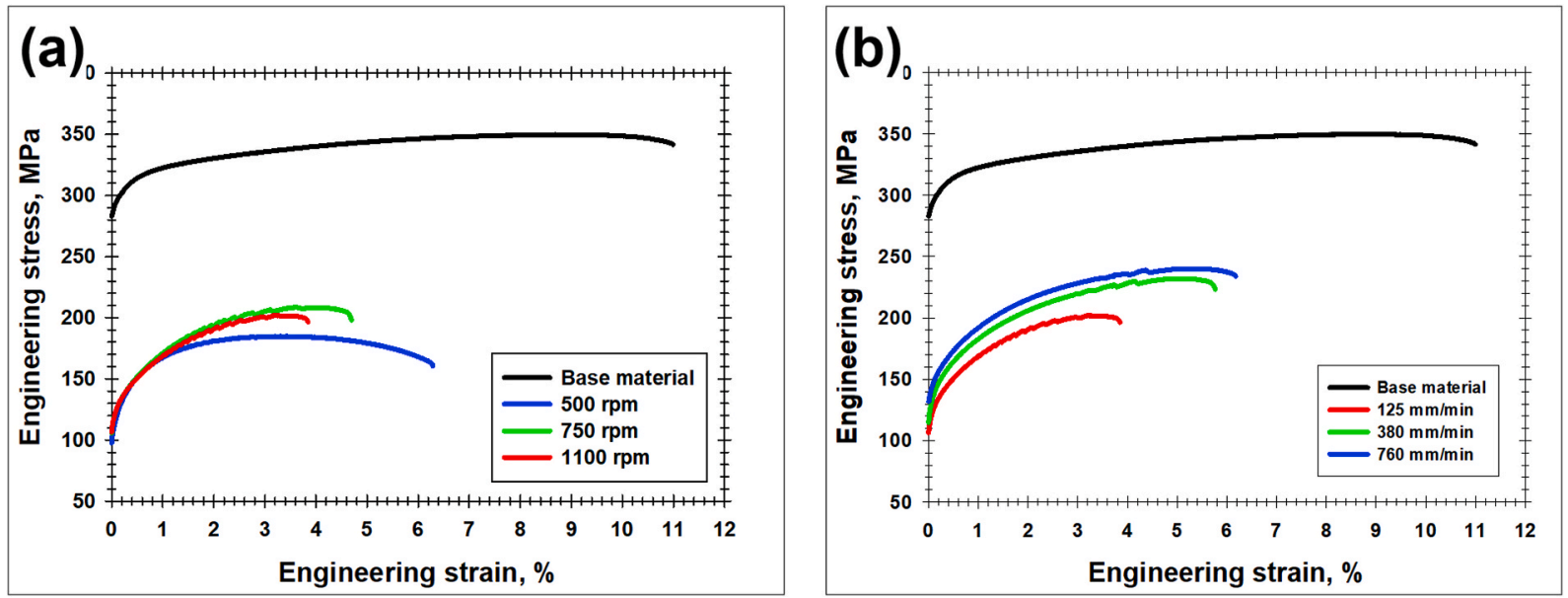

Fig. 9. Typical effect of the spindle rate (a) and feed rate (b) on transverse tensile behavior of friction-stir welds. In (a), the deformation diagrams are shown for the feed rate of $125 \mathrm{~mm} / \mathrm{min}$; in (b), the data were taken at the spindle rate of $1100 \mathrm{rpm}$. For comparison purpose, representative deformation diagram for base material is also shown.
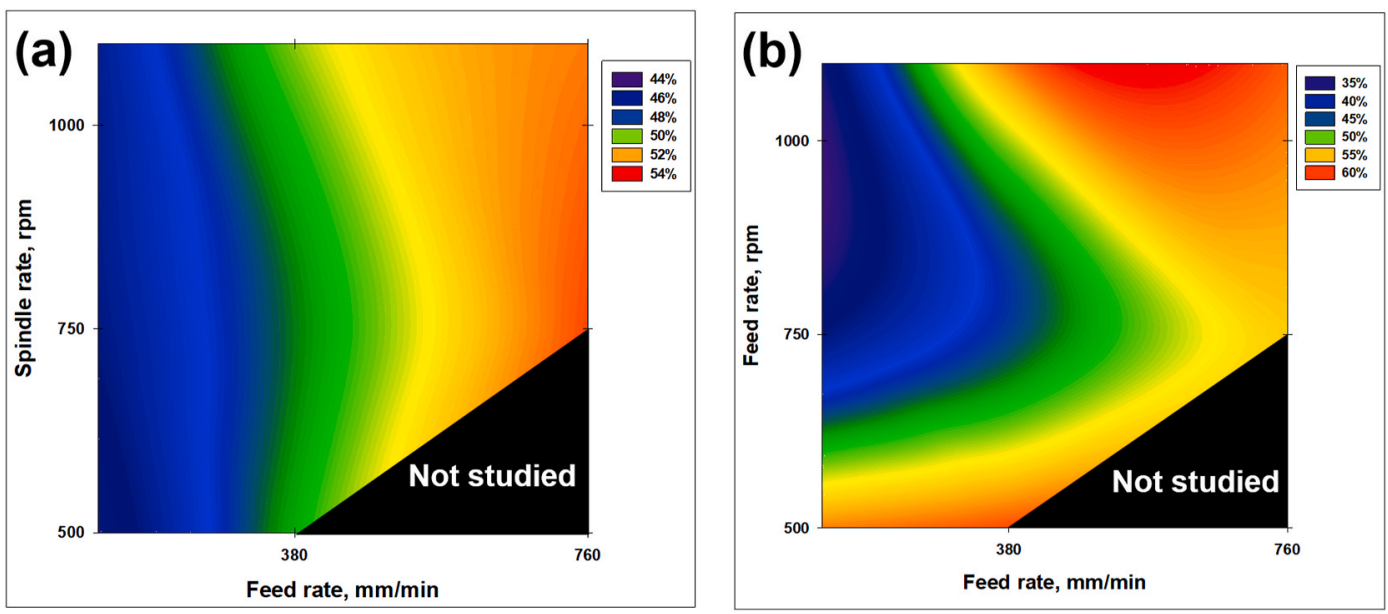

Fig. 10. Combined effect of the feed rate and the spindle rate on joint efficiency for yield strength (a) and elongation-to-failure (b).

(Fig. 10b) was presumably attributable to the fairly localized character material flow as well as a limited material plasticity in the heat affected zone.

\subsubsection{Fracture surface}

To investigate the failure behavior, the fracture surfaces of two representative welds, i.e., the $500-380$ and $1100-125$ ones, were examined, as shown in Fig. 14. In the low-heat-input weld, the fracture surface had a typical dimpled appearance (Fig. 14a) thus evidencing a ductile nature of failure. In the high-heat-input weld, the dimples were less pronounced; moreover, the contours of original elongated grains could be recognized (Fig. 14b). This presumably indicated a local crack propagation along original grain boundaries leading to the material decohesion. This observation was consistent with limited ductility of the 
Table 4

Mechanical properties of welds.

\begin{tabular}{|c|c|c|c|}
\hline Welds & $\begin{array}{l}\text { Yield strength, } \\
\mathrm{MPa}\end{array}$ & $\begin{array}{l}\text { Elongation to failure, } \\
\%\end{array}$ & Fracture location \\
\hline $500-125$ & $134 \pm 2$ & $5.8 \pm 0.2$ & Stir zone, Center \\
\hline 500-380 & $148 \pm 6$ & $6.0 \pm 0.2$ & Stir zone, Center \\
\hline $750-125$ & $137 \pm 7$ & $3.9 \pm 0.4$ & $\begin{array}{l}\text { Heat-affected } \\
\text { zone }\end{array}$ \\
\hline $750-380$ & $146 \pm 2$ & $5.5 \pm 1.7$ & Stir zone border \\
\hline $750-760$ & $159 \pm 4$ & $5.0 \pm 1.4$ & Stir zone border \\
\hline 1100-125 & $138 \pm 3$ & $3.6 \pm 0.3$ & $\begin{array}{l}\text { Heat-affected } \\
\text { zone }\end{array}$ \\
\hline $1100-380$ & $150 \pm 4$ & $5.8 \pm 0.3$ & $\begin{array}{l}\text { Heat-affected } \\
\text { zone }\end{array}$ \\
\hline $1100-760$ & $157 \pm 7$ & $6.0 \pm 0.7$ & $\begin{array}{l}\text { Heat-affected } \\
\text { zone }\end{array}$ \\
\hline $\begin{array}{l}\text { Base } \\
\text { material }\end{array}$ & $300 \pm 3$ & $10.2 \pm 1.2$ & - \\
\hline
\end{tabular}

Note: Error shows standard deviation.

heat-affected zone discussed in the previous section.

\section{Discussion}

\subsection{Relationship between weld thermal cycle and precipitation phenomena}

As shown above, the peak welding temperature varied from $254^{\circ} \mathrm{C}$ to $416^{\circ} \mathrm{C}$ and very often it was below $300{ }^{\circ} \mathrm{C}$ (i.e., the dissolution threshold for the $\beta$ phase). In this low-temperature range, quite expectedly, the precipitation coarsening and the concomitant coherency loss was observed. In stir zone of such low-temperature welds, the precipitates additionally undergone a fragmentation and/or coagulation due to the extensive plastic strain at elevated temperature. Moreover, a dispersion of original grain-boundary particles as well as a tool wear could also occur. Nevertheless, despite a high fraction of secondary particles as well as a formation of fine-grained structure, the hardness of the stirzone material in such low-heat-input welds was essentially lower than that in the high-heat-input ones (compare Fig. 5a and c).

To investigate this unusual effect, a relationship between the peak temperature, cooling rate and the average microhardness in the stir zone was plotted in Fig. 15. From the figure, it is seen that the relatively high strength was observed at the welding temperatures above $\sim 400^{\circ} \mathrm{C}$. This result is easy to explain in terms of re-precipitation of the dissolved dispersoids during weld cooling cycle, as is often reported in scientific literature [3,12,15-19,30,36].

Of particular interest, however, was the revealed increase of the material hardness with the cooling rate (Fig. 15). From a broad perspective, such thermal cycles should suppress the particle precipitation and thus result in a softening effect. This apparent controversy could be explained in terms of solute clustering. Specifically, the high cooling rate should preserve a substantial portion of vacancies generated during extensive high-temperature strain. In turn, the vacancies are known to be the key issue for the clustering of solutes [44]. As has been shown recently, such clusters could exert a significant strengthening effect [45].

It was suggested therefore that the relatively high hardness measured in the stir zone of the high-temperature welds was associated not only with re-precipitation of secondary particles but also with formation of solute clusters. It should be emphasized, however, that the latter idea is purely speculative at present and warrants experimental verification.

\subsection{Relationship between precipitation behavior and mechanical properties}

As suggested above, the material softening associated with

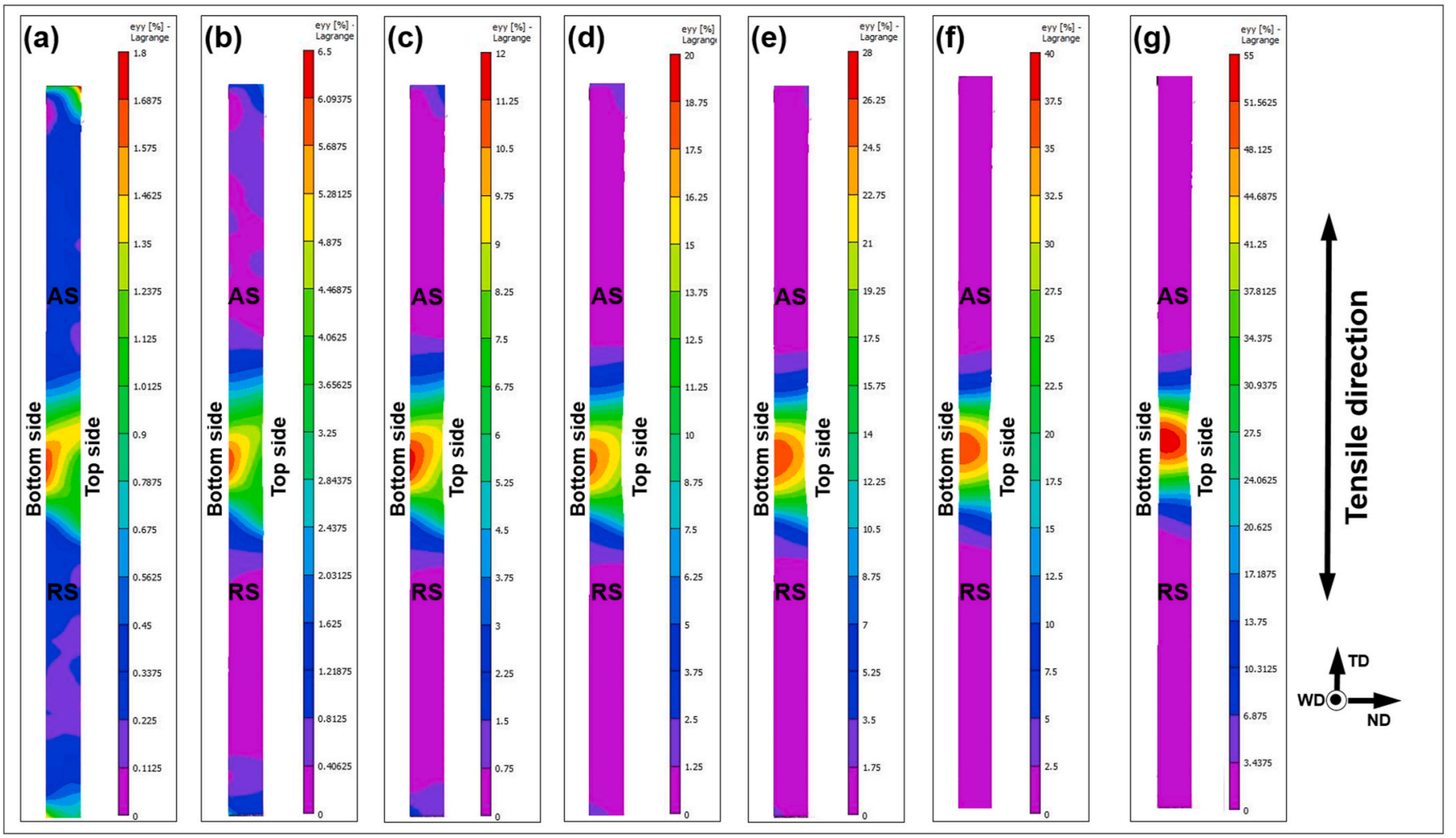

Fig. 11. Typical distribution of local longitudinal strains on a side surface of 500-380 weld (i.e., a low heat-input weld) evolved during transverse tensile test after global elongation of $0,2 \%$ (a), $1 \%$ (b), $2 \%$ (c), $3 \%$ (d), $4 \%$ (e), $5 \%$ (f), and immediately before failure (g). AS and RS abbreviate advancing side and retreating side, respectively. 


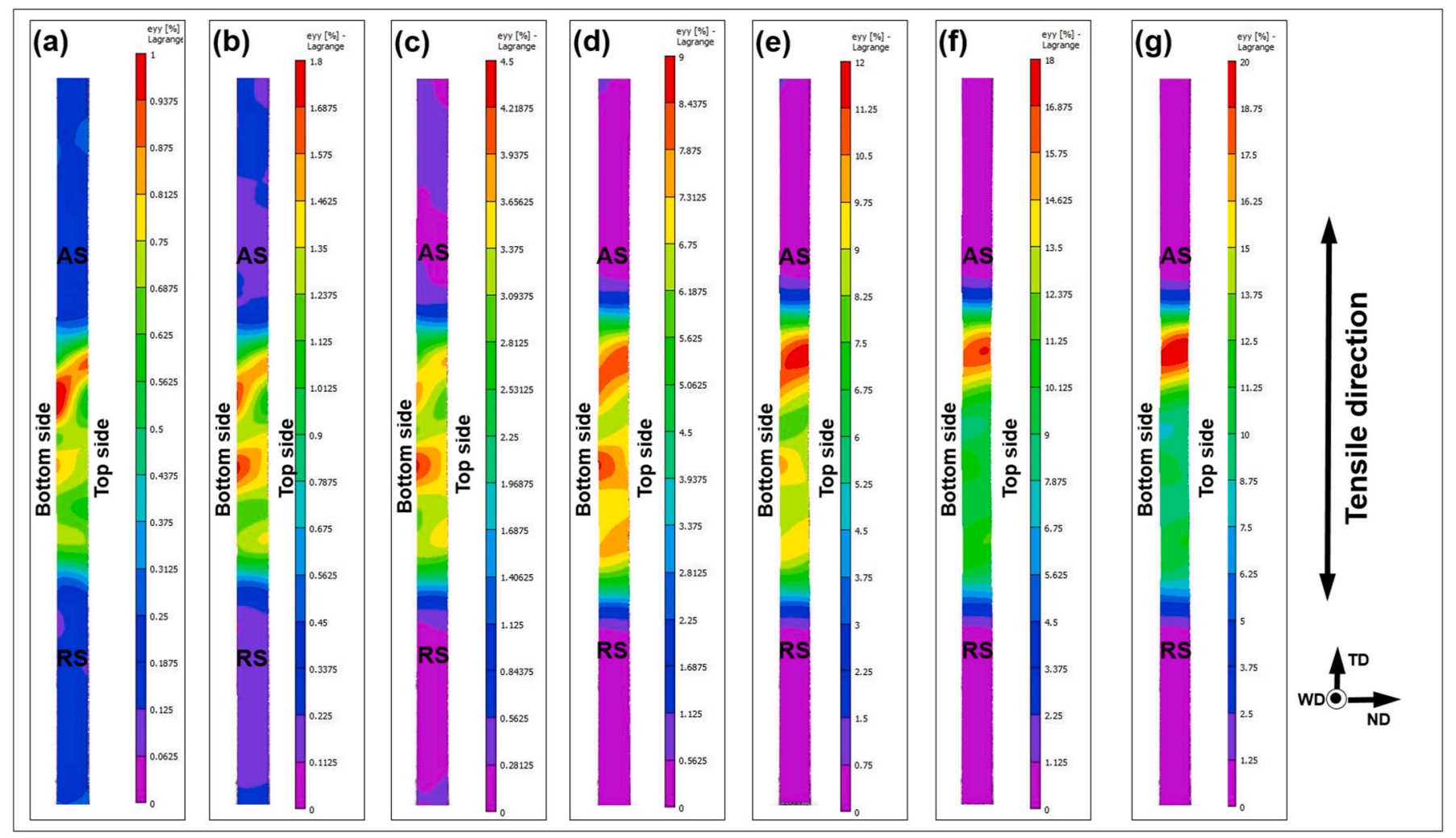

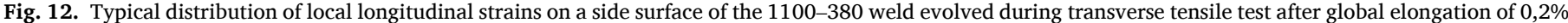

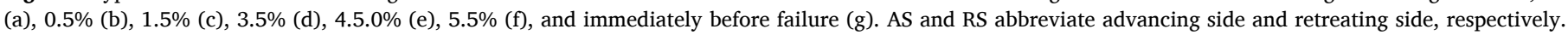

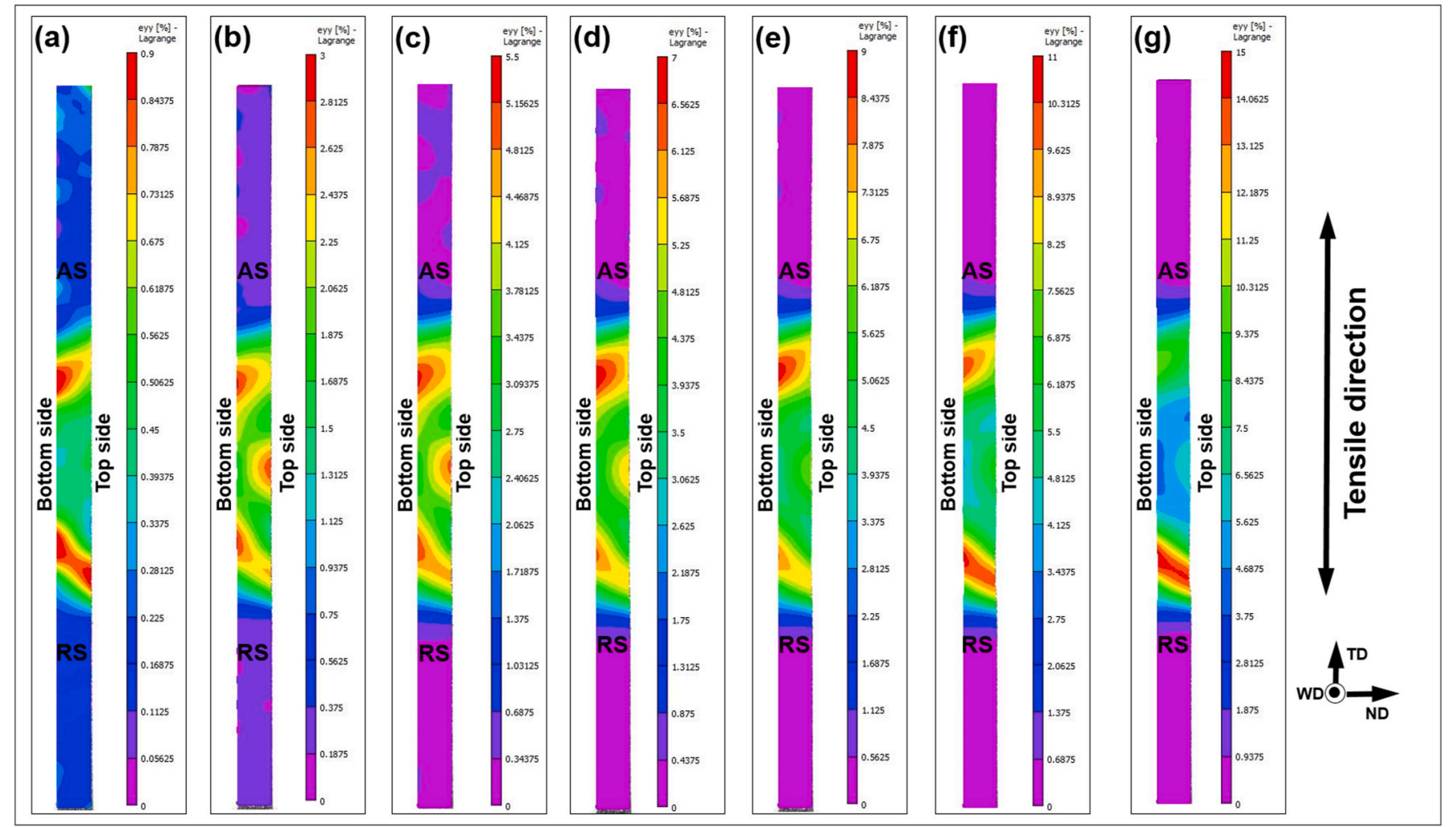

Fig. 13. Typical distribution of local longitudinal strains on a side surface of the 1100-125 weld (i.e., a high heat-input weld) evolved during transverse tensile test after global elongation of $0,2 \%(\mathrm{a}), 1 \%(\mathrm{~b}), 2 \%(\mathrm{c}), 2.5 \%(\mathrm{~d}), 3 \%(\mathrm{e}), 3.5 \%(\mathrm{f})$, and immediately before failure (g). AS and RS abbreviate advancing side and retreating side, respectively. 

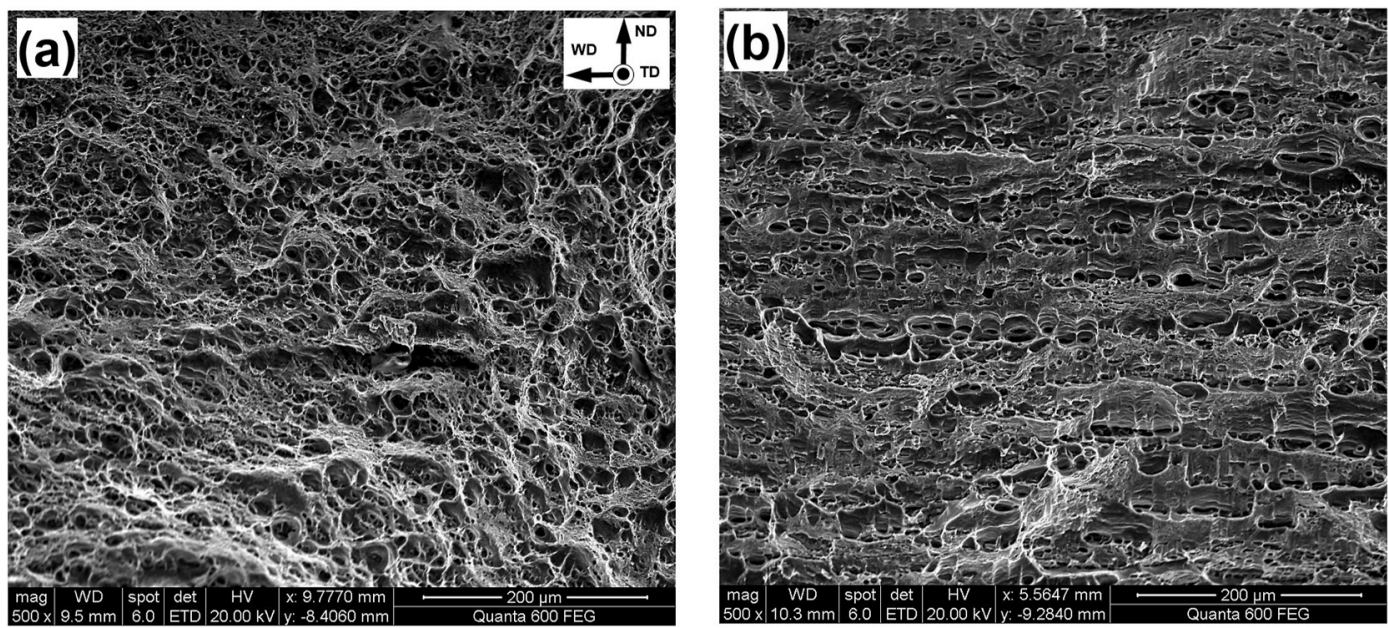

Fig. 14. SEM micrographs showing typical fracture surface of the 500-380 weld (i.e., a low heat-input weld) (a), and the 1100-125 weld (i.e., a high heat-input weld) (b) failed during transverse tensile tests. The reference frame for both micrographs is shown in the top right corner of (a).

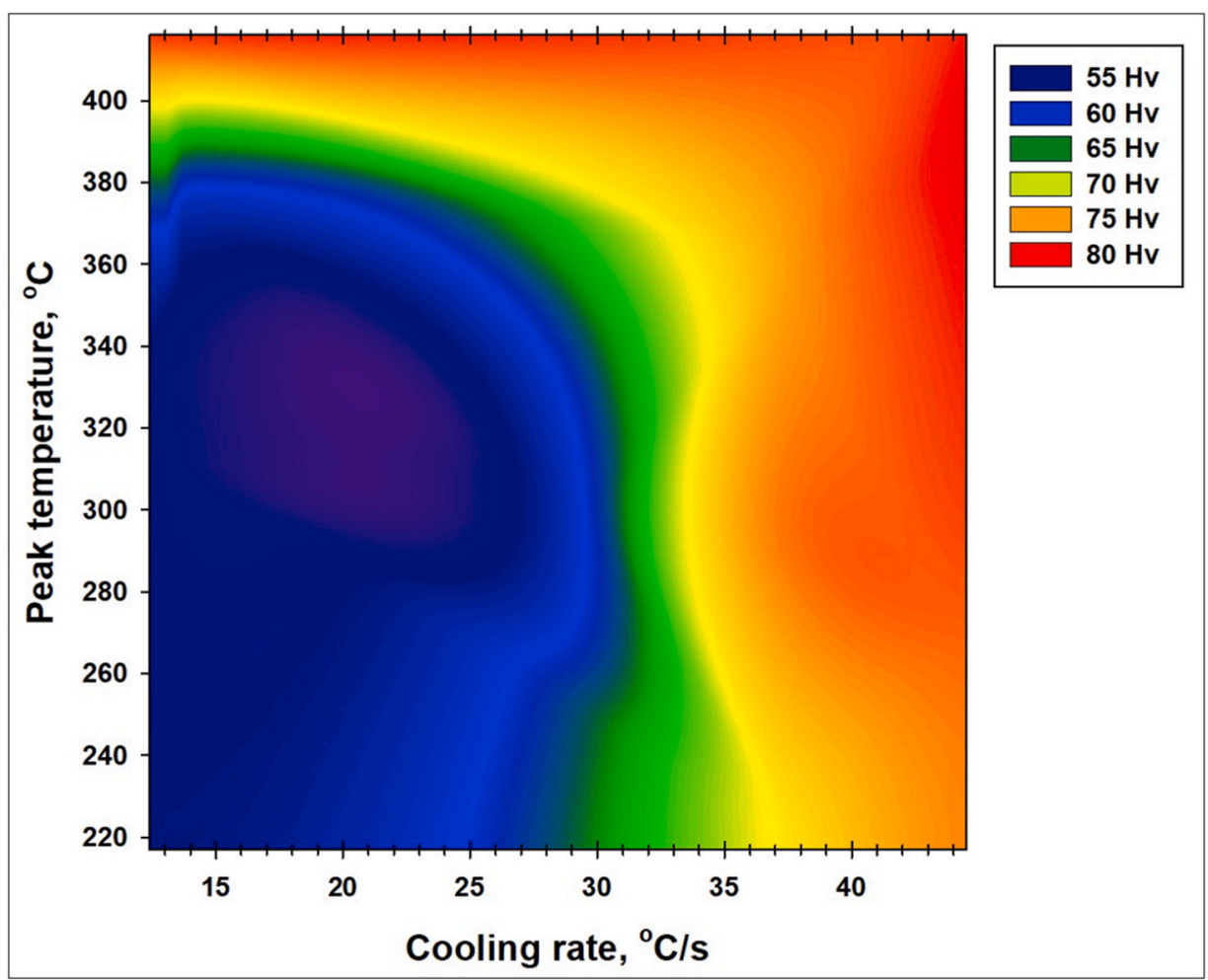

Fig. 15. Combined effect of peak temperature and average cooling rate on average microhardness in stir zone.

dissolution of the strengthening precipitates was partially compensated by the re-precipitation effect. Therefore, it could be surmised that the weld strength should be primarily governed by the precipitation coarsening. Due to the diffusion-driven nature of the latter process, it is critically sensitive to a duration of the weld thermal cycle, which, in turn, is known to be controlled by the feed rate. Therefore, the feed rate appears to be the key welding variable determining the weld strength. This conclusion is in excellent agreement with experimental results (Fig. 10a).

The material softening occurring during FSW inevitably gives rise to the strain localization during subsequent tensile tests of the produced welds. Accordingly, the weld ductility is critically dependent on the relative width of the softened zone. In the high-heat-input welds, the softening effect is most pronounced in the heat-affected zone (Fig. 5c).
Accordingly, the tensile strain is localized in this narrow microstructural region (Fig. 13) and thus the global weld ductility is low (Fig. 10b). In the low-heat-input welds, the softest area is the stir zone (Fig. 5a). Therefore, the tensile strain concentrates in this relatively wide microstructural area (Fig. 11) and total elongation is relatively high (Fig. 10b). In the "intermediate" range of the weld thermal cycle, where the softening effect in the heat-affected zone and the re-precipitation hardening in the stir zone nearly compensate each other, the width of the softened region is the largest (Fig. 5b). As a result, the weld ductility is highest (Fig. 10b).

\subsection{Quantification of strengthening mechanisms}

In order to provide a quantitative insight into weld strength, the 
contribution of different hardening mechanisms into global yield strength was evaluated in two representative joints, i.e., the 500-380 and $1100-125$ ones. In the former case, the plastic deformation initiated in the stir zone (Fig. 11a) whereas that in the latter weld occurred in the heat-affected zone (Fig. 13a). The relevant microstructural characteristics of these microstructural regions are summarized in Table 5.

Assuming that the different hardening mechanisms have additive contributions and considering the relatively low dislocation density in all cases (Figs. 6 and 8), the total strength $\sigma$ could be expressed as:

$\sigma=\sigma_{0}+\sigma_{p}+\sigma_{G B}$

where $\sigma_{0}$ is the threshold stress, $\sigma_{p}$ denotes precipitation hardening, and $\sigma_{G B}$ is grain-boundary strengthening. ${ }^{5}$

In the studied material, the threshold stress could be evaluated as:

$\sigma_{0}=\sigma_{0}^{A l}+\sigma_{s s}=\sigma_{0}^{A l}+H_{M g} C_{M g}$

where $\sigma_{o}^{A l}$ is the threshold stress in pure aluminum ( $\left.\approx 10 \mathrm{MPa}\right), \sigma_{s s}$ is the solid-solution strengthening, $H_{M g}$ is the solid-solution strengthening efficiency of magnesium solutes (taken to be $13.8 \mathrm{MPa} / \mathrm{wt} . \% \mathrm{Mg}$ [46]), and $C_{M g}$ is wt.\% of magnesium. As followed from ThermoCalc calculations, however, the magnesium content in aluminum matrix was relatively low $(0.1 \mathrm{wt} \%$ in the 500-380 weld and $0.05 \mathrm{wt} \%$ in the $1100-125$ weld). Accordingly, the solid-solution strengthening was assumed to be negligible low and thus the threshold stress was accepted to be $10 \mathrm{MPa}$.

Considering significant coarsening of the strengthening precipitates (and the concomitant coherency loss), the precipitation hardening was presumably governed by the Orowan mechanism. Accordingly, the strengthening effect could be calculated as:

$\sigma_{p}=\frac{M G b}{\lambda-2 r}$

where $M$ is Taylor factor (taken to be 3 ), $G$ is the shear modulus of aluminum $(\approx 25.4 \mathrm{GPa}), b$ is the Burgers vector $(=0.286 \mathrm{~nm}), \lambda$ is the particle mean spacing, and $r$ is either the particle half-width or the particle radius (given in Table 5). In turn, the particle mean spacing could be evaluated as:

Table 5

Microstructural characteristics used for quantification of hardening mechanisms.

\begin{tabular}{lllllll}
\hline \multirow{2}{*}{ Weld } & \multicolumn{2}{l}{ Second-phase particles } & & Grain structure & & \\
\cline { 2 - 3 } \cline { 5 - 6 } & $\begin{array}{l}\text { Half- } \\
\text { thickness } \\
\text { or radius } \\
(\mathrm{r}), \mathrm{nm}\end{array}$ & $\begin{array}{l}\text { Volume } \\
\text { fraction } \\
(\mathrm{f})\end{array}$ & & $\begin{array}{l}\text { Mean LAB } \\
\text { misorientation } \\
\left(\Theta_{\mathrm{LAB}}\right), \text { rad }\end{array}$ & $\begin{array}{l}\text { HAB } \\
\text { fraction } \\
\left(\mathrm{f}_{\mathrm{HAB}}\right)\end{array}$ & $\begin{array}{l}\text { Mean } \\
\text { grain- } \\
\text { boundary } \\
\text { intercept } \\
\left(\mathrm{D}_{\mathrm{GB}}\right) \mu \mathrm{m}\end{array}$ \\
\hline $500-380$ & 22 & 0.0184 & 0.14 & & 0.74 & 1.3 \\
$1100-125$ & 13 & 0.0026 & 0.12 & 0.68 & 4.5 \\
\hline
\end{tabular}

Note: In the 500-380 weld, the second-phase precipitates presumably constituted a mixture of $\beta$ phase and the Fe-rich former grain-boundary particles dispersed in the stir zone during FSW. In the 1100-125 weld, the dispersoids belonged to the $\beta^{\prime}$ - (and/or $\beta$ ) as well as Q phases evolved in the heat-affected zone.

\footnotetext{
${ }^{5}$ According to Fig. 15, an essential hardening effect associated with solute clustering was predicted at the temperatures above $\sim 400{ }^{\circ} \mathrm{C}$ or the cooling rates exceeding $\sim 35{ }^{\circ} \mathrm{C} / \mathrm{s}$. None of these conditions were measured in the stir zone of the 500-380 weld and the heat-affected zone of the 1100-125 weld. Accordingly, the strengthening effect of the solute clusters was not considered in Section 4.3.
}

$\lambda=\sqrt{\frac{2 \pi r^{2}}{3 f}}$

where $f$ is the particle volume fraction (shown in Table 5).

The calculated contributions of the precipitation hardening were summarized in Table 6.

Considering a complex character of the evolved grain structure, which consisted of a mixture of LABs and HABs (Fig. 7), the grainboundary strengthening could be estimated as [47]:

$\sigma_{G B}=\frac{M G \alpha \sqrt{3 b \Theta_{L A B}\left(1-f_{H A B}\right)}+k_{H P} \sqrt{f_{H A B}}}{\sqrt{D_{G B}}}$

where $\alpha$ is a constant (often taken to be 0.24 in aluminum alloys), $\Theta_{L A B}$ is the mean LAB misorientation, $f_{H A B}$ is the HAB fraction, $k_{H P}$ is the HallPetch constant (taken to be $0.17 \mathrm{MPa} \times \mathrm{m}^{1 / 2}$ in the present work [48]), and $D_{G B}$ is the mean grain boundary intercept. The mean LAB misorientation, HAB fraction and the mean grain-boundary intercept were derived from EBSD data and summarized in Table 5. The calculated contributions of the grain-boundary strengthening were given in Table 6.

From this table, it is seen that the summing of contributions of all strengthening mechanisms resulted in essential overestimation of the weld yield strength in both studied cases. On the other hand, a consideration of only solution- and precipitation hardenings in the 1100-125 weld gave excellent agreement with experimental data. It could be suggested therefore that the grain structure exerted only minor influence on the yielding behavior and the weld strength in this case was mainly governed by the precipitation strengthening. Considering a relatively coarse-grained microstructure of the heat-affected zone, this assumption seems to be reasonable.

In the 500-380 weld, however, the predicted precipitation hardening was found to be essentially below the measured material strength (Table 6). Taking into account a very fine-grained microstructure evolved in the stir zone (Table 3), it is likely that the grain-boundary strengthening also contributed to the yield strength. If so, the revealed disagreement between the experimental data and the predictions may be due to the non-additive contributions of the precipitation- and grainboundary strengthening mechanisms in a complex microstructure similar to that observed in the stir zone.

\section{Conclusions}

This work was undertaken in an attempt to establish a better understanding of the microstructure-strength relationship in friction-stir welded heat-treatable aluminum alloys. To this end, 6061-T6 aluminum alloy was selected as a program material and FSW was conducted in relatively wide range of processing conditions including a variation of a spindle rate from 500 to $1100 \mathrm{rpm}$ and a feed rate from 125 to $760 \mathrm{~mm} / \mathrm{min}$. In all cases, the weld thermal cycle was recorded, the evolved microstructures were examined by using EBSD and TEM techniques, and tensile behavior of the produced welds was studied with application of DIC approach. The main conclusions derived from this work were as follows.

Depending on welding conditions, the peak welding temperature in the stir zone was found to vary from 254 to $416^{\circ} \mathrm{C}$, often being below

Table 6

Contributions of strengthening mechanisms.

\begin{tabular}{lllllll}
\hline \multirow{2}{*}{ Weld } & \multicolumn{9}{l}{ Predicted strength, MPa } & $\begin{array}{l}\text { Measured yield } \\
\text { strength, MPa }\end{array}$ \\
\cline { 2 - 5 } & $\sigma_{0}$ & $\sigma_{p}$ & $\sigma_{G B}$ & $\begin{array}{l}\sigma_{0}+\sigma_{p}+ \\
\sigma_{G B}\end{array}$ & $\begin{array}{l}\sigma_{0}+ \\
\sigma_{p}\end{array}$ \\
\hline $500-380$ & 10 & 113 & 106 & 229 & 123 & 148 \\
$1100-125$ & & 127 & 67 & 204 & 137 & 138 \\
\hline
\end{tabular}


$300{ }^{\circ} \mathrm{C}$ (i.e., the dissolution threshold for the strengthening $\beta$ phase). On the other hand, the peak temperature never exceeded $500{ }^{\circ} \mathrm{C}$ and thus the $\beta$ phase never dissolved completely. The average cooling rate ranged from 12.4 to $44.5^{\circ} \mathrm{C} / \mathrm{s}$ thereby being well below of that expected during water quenching.

In all cases, a drastic grain refinement was observed in the stir zone. The evolved grain structure was dominated by recrystallized grains with a mean $\mathrm{HAB}$ intercept varying from 2 to $7 \mu \mathrm{m}$ and a HAB fraction ranging from 62 to $77 \%$. At relatively low welding temperatures, quite expectedly, the precipitation behavior was governed by the coarsening mechanism which led to the coherency loss. Additionally, however, some evidences of fragmentation and dispersion of grain-boundary particles as well as the tool wear were found. In the high-temperature welds, the particle dissolution was deduced to be followed by the reprecipitation of solute clusters during weld cooling cycle.

It was shown that the weld strength was essentially influenced by the precipitation coarsening and particle dissolution. Both these phenomena resulted in material softening but the particle dissolution was partially compensated by the subsequent re-precipitation of solute clusters. Accordingly, the precipitation coarsening was inferred to be the major softening mechanism. Due to the diffusion-driven nature of this process, it is critically sensitive to a duration of the weld thermal cycle, which, in turn, is known to be controlled by the feed rate. Therefore, the welding speed was deduced to be the key factor determining the weld strength.

\section{Data availability}

All data included to this study are available upon request by contact with corresponding author.

\section{Declaration of competing interest}

The authors declare that they have no known competing financial interests or personal relationships that could have appeared to influence the work reported in this paper.

\section{CRediT authorship contribution statement}

Alexander Kalinenko: Investigation, Validation, Writing - review \& editing. Konstantin Kim: Investigation, Validation. Igor Vysotskiy: Methodology, Investigation, Validation. Ivan Zuiko: Investigation, Writing - review \& editing. Sergey Malopheyev: Methodology, Investigation, Validation, Formal analysis, Writing - review \& editing. Sergey Mironov: Conceptualization, Funding acquisition, Project administration, Formal analysis, Visualization, Writing - original draft. Rustam Kaibyshev: Conceptualization, Supervision, Resources, Funding acquisition, Writing - review \& editing.

\section{Acknowledgments}

This study was financially supported by the Russian Science Foundation, grant No. 19-49-02001. The authors are also grateful to the staff of the Joint Research Center "Technology and Materials" at Belgorod State National Research University for assistance in experimental works.

\section{Appendix A. Supplementary data}

Supplementary data to this article can be found online at https://doi. org/10.1016/j.msea.2020.139858.

\section{References}

[1] R.S. Mishra, Z.Y. Ma, Friction stir welding and processing, Mater. Sci. Eng. R 50 (2005) 1-78, https://doi.org/10.1016/j.mser.2005.07.001.

[2] P.L. Threadgill, A.J. Leonard, H.R. Shercliff, P.J. Withers, Friction stir welding of aluminum alloys, Int. Mater. Rev. 54 (2009) 49-93, https://doi.org/10.1179/ $174328009 \times 411136$.
[3] J.-Q. Su, T.W. Nelson, R. Mishra, M. Mahoney, Microstructural investigation of friction stir welded 7050-T651 aluminum, Acta Mater. 51 (2003) 713-729, https:// doi.org/10.1016/s1359-6454(02)00449-4.

[4] K.V. Jata, K.K. Sankaran, J.J. Ruschau, Friction-stir welding effects on microstructure and fatigue of aluminum alloy 7050-T7451, Metall. Mater. Trans. A 31 (2000) 2181-2192, https://doi.org/10.1007/s11661-000-0136-9.

[5] M. Dumont, A. Steuwer, A. Deschamps, M. Peel, P.J. Withers, Microstructure mapping in friction stir welds of 7449 aluminum alloy using SAXS, Acta Mater. 54 (2006) 4793-4801, https://doi.org/10.1016/j.actamat.2006.06.015.

[6] Y.S. Sato, H. Kokawa, M. Enomoto, S. Jogan, Microstructural evolution of 6063 aluminum during friction-stir welding, Metall. Mater. Trans. A 30 (1999) 2429-2437, https://doi.org/10.1007/s11661-999-0251-1.

[7] B. Heinz, B. Skrotzki, Characterization of a friction-stir-welded aluminum alloy 6013, Metall. Mater. Trans. B 33 (2002) 489-498, https://doi.org/10.1007/ s11663-002-0059-5.

[8] M. Cabibbo, H.J. McQueen, E. Evangelista, S. Spigarelli, M.D. Paola, A. Falchero, Microstructure and mechanical property studies of AA6056 friction stir welds, Mater. Sci. Eng. A 460-461 (2007) 86-94, https://doi.org/10.1016/j. msea.2007.01.022.

[9] W. Woo, H. Choo, D.W. Brown, Z. Feng, Influence of the tool pin and shoulder on microstructure and natural aging kinetics in a friction-stir-processed 6061-T6 aluminum alloy, Metall. Mater. Trans. A 38 (2007) 69-76, https://doi.org/ 10.1007/s11661-006-9034-0.

[10] C. Gallais, A. Denquin, Y. Brechet, G. Lapasset, Precipitation microstructures in an AA6056 aluminum alloy after friction stir welding: characterization and modelling, Mater. Sci. Eng. A 496 (2008) 77-89, https://doi.org/10.1016/j. msea.2008.06.033.

[11] A. Sumar, Y. Brechet, B. de Meester, A. Denquin, T. Pardoen, Microstructure, local and global mechanical properties of friction stir welds in aluminum alloy 6005AT6, Mater. Sci. Eng. 486 (2008) 85-95, https://doi.org/10.1016/j. msea.2007.08.041.

[12] P. Dong, D. Sun, H. Li, Natural aging behavior of friction stir welded 6005A-T6 aluminum alloy, Mater. Sci. Eng. A 576 (2013) 29-35, https://doi.org/10.1016/j. msea.2013.03.077.

[13] C.S. Paglia, R.G. Buchheit, Microstructure, microchemistry and environmental cracking susceptibility of friction stir welded 2219-T87, Mater. Sci. Eng. A 429 (2006) 107-114, https://doi.org/10.1016/j.msea.2006.05.036.

[14] P.B. Srinivasan, K.S. Arora, W. Dietzel, S. Pandey, M.K. Schaper, Characterization of microstructure, mechanical properties and corrosion behavior of an AA2219 friction stir weldment, J. Alloys Compd. 492 (2010) 631-637, https://doi.org/ 10.1016/j.jallcom.2009.11.198.

[15] C. Genevois, A. Deschamps, A. Denquin, B. Doisneau-Cottignies, Quantitative investigation of precipitation and mechanical behavior for AA2024 friction stir welds, Acta Mater. 53 (2005) 2447-2458, https://doi.org/10.1016/j. actamat.2005.02.007.

[16] M.J. Jones, P. Heurtier, C. Desrayaud, F. Montheillet, D. Allehaux, J.H. Driver, Correlation between microstructure and microhardness in a friction stir welded 2024 aluminum alloy, Scripta Mater. 52 (2005) 693-697, https://doi.org/ 10.1016/j.scriptamat.2004.12.027.

[17] R.W. Fonda, J.F. Bingert, Microstructural evolution in the heat-affected zone of a friction stir weld, Metall. Mater. Trans. A 35 (2004) 1487-1499, https://doi.org/ 10.1007/s11661-004-0257-7.

[18] R.W. Fonda, J.F. Bingert, Precipitation and grain refinement in a $2195 \mathrm{Al}$ friction stir weld, Metall. Mater. Tran. 37 (2006) 3593-3604, https://doi.org/10.1007/ s11661-006-1054-2.

[19] A. Sullivan, J.D. Robson, Microstructural properties of friction stir welded and post-weld heat-treated 7449 aluminum alloy thick plate, Mater. Sci. Eng. A 478 (2008) 351-360, https://doi.org/10.1016/j.msea.2007.06.025.

[20] A. Steuwer, M. Dumont, J. Altenkirch, S. Birosca, A. Deschamps, P.B. Prangnell, P. J. Withers, A combined approach to microstructure mapping of an Al-Li AA2199 friction stir weld, Acta Mater. 59 (2011) 3002-3011, https://doi.org/10.1016/j. actamat.2011.01.040.

[21] J. Kang, Z.C. Feng, G. Frankel, I.W. Huang, G.Q. Wang, A.P. Wu, Friction stir welding of Al alloy 2219-T8: part I-evolution of precipitates and formation of abnormal $\mathrm{Al}_{2} \mathrm{Cu}$ agglomerates, Metall. Mater. Trans. 47 (2016) 4553-4565, https://doi.org/10.1007/s11661-016-3648-7.

[22] F. De Geuser, B. Malard, A. Deschamps, Microstructure mapping of a friction stir welded AA2050 Al-Li-Cu in the T8 state, Phil. Mag. 94 (2014) 1451-1462, https://doi.org/10.1080/14786435.2014.887862.

[23] Y. Chen, J. Feng, H. Liu, Precipitate evolution in friction stir welding of 2219-T6 aluminum alloys, Mater. Char. 60 (2009) 476-481, https://doi.org/10.1016/j. matchar.2008.12.002.

[24] A. Simar, Y. Brechet, B. de Meester, A. Denquin, T. Pardoen, Sequential modeling of local precipitation, strength and strain hardening in friction stir welds of an aluminum alloy 6005A-T6, Acta Mater. 55 (2007) 6133-6143, https://doi.org/ 10.1080/14786435.2014.887862, j.

[25] N. Martinez, N. Kumar, R.S. Mishra, K.J. Doherty, Effect of tool dimensions and parameters on the microstructure of friction stir welded aluminum 7449 alloy of various thicknesses, Mater. Sci. Eng. A 684 (2017) 470-479, https://doi.org/ 10.1016/j.msea.2016.12.077.

[26] M.W. Mahoney, M.C.G. Rhodes, J.G. Flintoff, W.H. Bingel, R.A. Spurling, Properties of friction-stir-welded 7075 T651 aluminum, Metall. Mater. Trans. 29 (1998) 1955-1964, https://doi.org/10.1007/s.11661-998-0021-5.

[27] N. Kamp, A. Sullivan, R. Tomas, J.D. Robson, Modelling of heterogeneous precipitate distribution evolution during friction stir welding process, Acta Mater. 54 (2006) 2003-2014, https://doi.org/10.1080/14786435.2014.887862. 
[28] A. Sullivan, J. Robson, Microstructural properties of friction stir welded and postweld heat-treated 7449 aluminium alloy thick plate, Mater. Sci. Eng. A 478 (2008) 351-360, https://doi.org/10.1016/j.msea.2007.06.025.

[29] X. Feng, H. Liu, J.C. Lippold, Microstructure characterization of the stir zone of submerged friction stir processed aluminum alloy 2219, Mater. Char. 82 (2013) 97-102, https://doi.org/10.1016/j.matchar.2013.05.010.

[30] C.G. Rhodes, M.W. Mahoney, W.H. Bingel, R.A. Spurling, C.C. Bampton, Effects of friction stir welding on microstructure of 7075 aluminum, Scripta Mater. 36 (1997) 69-75, https://doi.org/10.1016/S1359-6462(96)00344-2.

[31] A.H. Feng, D.L. Chen, Z.Y. Ma, Microstructure and cyclic deformation behavior of a friction-stir-welded $7075 \mathrm{Al}$ alloy, Metall. Mater. Trans. A 41 (2010) 957-971, https://doi.org/10.1007/s11661-009-0152-3.

[32] A.H. Feng, D.L. Chen, Z.Y. Ma, Microstructure and low-cycle fatigue of a frictionstir welded 6061 aluminum alloy, Metall. Mater. Trans. A 41 (2010) 2626-2641, https://doi.org/10.1007/s11661-010-0279-2.

[33] C.A.W. Olea, L. Roldo, J.F. dos Santos, T.R. Strohaecker, A substructural analysis of friction stir welded joints in an AA6056 Al-alloys in T4 and T6 temper conditions, Mater. Sci. Eng. A 454-455 (2007) 52-62, https://doi.org/10.1016/j. msea.2006.12.055.

[34] B. Cai, Z.Q. Zheng, D.Q. He, S.C. Li, H.P. Li, Friction stir weld of 2060 Al-Cu-Li alloy: microstructure and mechanical properties, J. All. Comp. 649 (2015) 19-27, https://doi.org/10.1016/j.jallcom.2015.02.124.

[35] T.L. Giles, K. Oh-Ishi, A.P. Zhilyaev, S. Swaminathan, M.W. Mahoney, T. R. McNelley, The effect of friction stir processing on the microstructure and mechanical properties of an aluminum lithium alloy, Metall. Mater. Trans. A 40 (2009) 104-115, https://doi.org/10.1007/s11661-008-9698-8.

[36] H. Qin, H. Zhang, H. Wu, The evolution of precipitation and microstructure in friction stir welded 2195-T8 Al-Li alloy, Mater. Sci. Eng. A 626 (2015) 322-329, https://doi.org/10.1016/j.msea.2014.12.026.

[37] S. Malopheyev, I. Vysotskiy, V. Kulitskiy, S. Mironov, R. Kaibyshev, Optimization of processing-microstructure-properties relationship in friction-stir welded 6061T6 aluminum alloy, Mater. Sci. Eng. A 662 (2016) 136-143, https://doi.org/ 10.1016/j.msea.2016.03.063.
[38] C. Cao, Z. Zhu, J. Han, H. Li, Correlation of microstructure and mechanical properties in friction stir welded 2198-T8 Al-Li alloy, Mater. Sci. Eng. A 639 (2015) 489-499, https://doi.org/10.1016/j.msea.2015.05.038.

[39] S. Mironov, K. Inagaki, Y.S. Sato, H. Kokawa, Effect of welding temperature on microstructure of friction-stir welded aluminum alloy 1050, Metal. Mater. Trans. A 46 (2015) 783-790, https://doi.org/10.1007/s11661-014-2651-0.

[40] I.V. Vysotskiy, S.S. Malopheyev, S.Y. Mironov, R.O. Kaibyshev, Optimization of friction-stir welding of 6061-T6 aluminum alloy, Phys. Mesomech. 22 (2019) 58-83, https://doi.org/10.24411/1683-805X-2019-16006.

[41] D.B. Williams, C.B. Carter, Transmission Electron Microscopy: A Textbook for Materials Science, third ed., Springer, New York, 2009.

[42] S. Mironov, K. Masaki, Y.S. Sato, H. Kokawa, Relationship between material flow and abnormal grain growth in friction-stir welds, Scripta Mater. 67 (2012) 983-986, https://doi.org/10.1016/j.scriptamat.2012.09.002.

[43] K. Chen, C. Liu, J. Yang, P. Ma, L. Zhan, M. Huang, J. Li, Stabilizing Al-Mg-Si-Cu alloy by precipitation nano-phase control, Mater. Sci. Eng. A 769 (2020) 138513, https://doi.org/10.1016/j.msea.2019.138513.

[44] S. Pogatscher, H. Antrekowitsch, H. Leitner, T. Ebner, P.J. Uggowitzer, Mechanisms controlling the artificial aging of Al-Mg-Si alloys, Acta Mater. 59 (2011) 3352-3363, https://doi.org/10.1016/j.actamat.2011.02.010.

[45] H. Li, W. Liu, Nanoprecipitates and their strengthening behavior in Al-Mg-Si alloy during the aging process, Metall. Mater. Trans. 48 (2017) 1990-1998, https://doi. org/10.1007/s11661-017-3955-7.

[46] T.J. Harrell, T.D. Topping, H. Wen, T. Hu, J.M. Schoenung, E.J. Lavernia, Microstructure and strengthening mechanisms in an ultrafine grained Al-Mg-Sc alloy produced by powder metallurgy, Metall. Mater. Trans. A 45 (2014) 6329-6343, https://doi.org/10.1007/s11661-014-2569-6.

[47] N. Hansen, Hall-Petch relation and boundary strengthening, Scripta Mater. 51 (2004) 801-806, https://doi.org/10.1016/j.scriptamat.2004.06.002.

[48] K.L. Kendig, D.B. Miracle, Strengthening mechanisms of an Al-Mg-Sc-Zr alloy, Acta Mater. 50 (2002) 4165-4175, https://doi.org/10.1016/S1359-6454(02)00258-6. 